\title{
Evaluation der Therapieoptionen der Appendizitis
}

\author{
INAUGURAL-DISSERTATION \\ zur Erlangung des Doktorgrades \\ der Medizinischen Fakultät der \\ Georg-August-Universität zu Göttingen
}

vorgelegt von

Florian Horst Armin Wendt (geb. Malinowsky)

aus

Kassel

Göttingen 2020 
Dekan:

Referent/in

Ko-Referent/in:

Drittreferent/in:

Datum der mündlichen Prüfung:
Prof. Dr. med. W. Brück

Prof. Dr. med. B. Reith

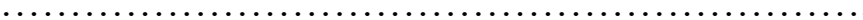

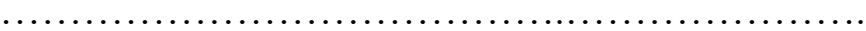


Dekan:

\section{Betreuungsausschuss}

Betreuer/in

Ko-Betreuer/in:

\section{Prüfungskommission}

Referent/in

Ko-Referent/in:

Drittreferent/in:

Datum der mündlichen Prüfung:
Prof. Dr. med. W. Brück

Prof. Dr. med. B. Reith

Privatdozent Dr. med. S. Kunsch 
Hiermit erkläre ich, die Dissertation mit dem Titel "Evaluation der Therapieoptionen der Appendizitis" eigenständig angefertigt und keine anderen als die von mir angegebenen Quellen und Hilfsmittel verwendet zu haben.

Göttingen, den

(Unterschrift) 


\title{
INHALTSVERZEICHNIS
}

\begin{abstract}
ABBILDUNGSVERZEICHNIS........................................................................ III

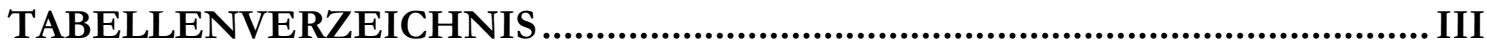

ABKÜRZUNGSVERZEICHNIS ...................................................................... III
\end{abstract}

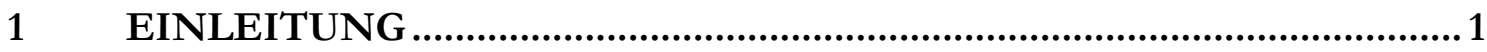

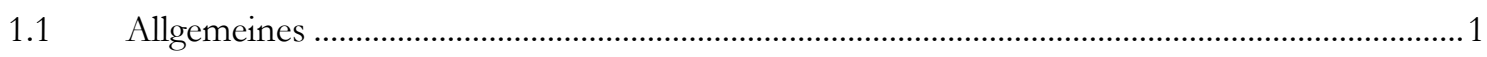

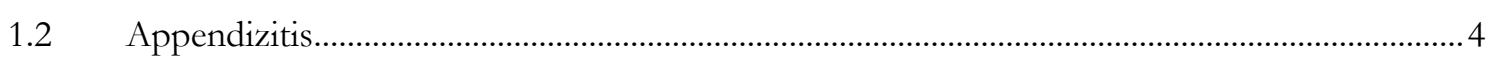

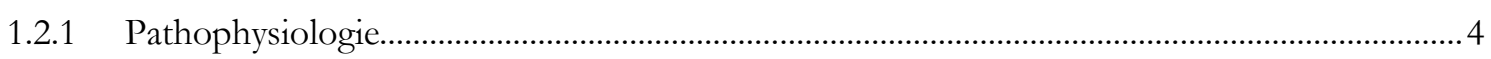

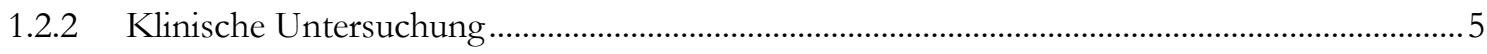

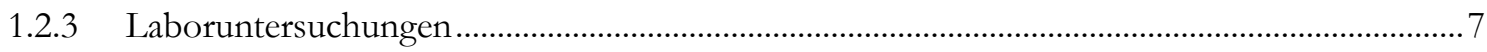

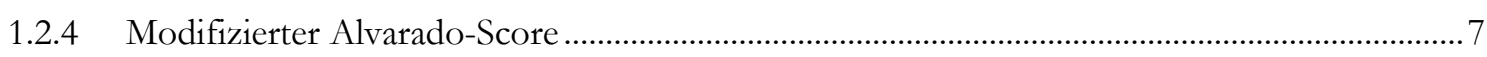

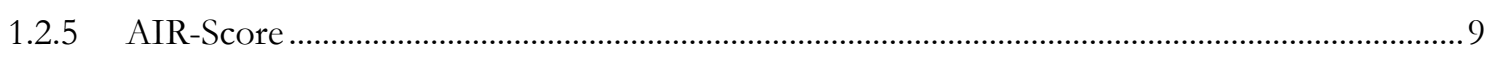

1.2.6 Sonografie des Abdomens bei Verdacht auf Appendizitis .......................................................10

1.2.7 Computertomografie des Abdomens bei Verdacht auf Appendizitis........................................11

1.2.8 Differentialdiagnosen zu einer Appendizitis ............................................................................11

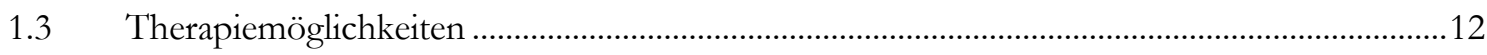

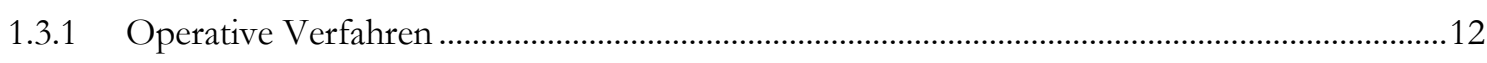

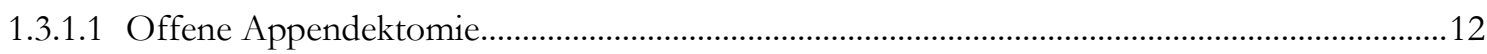

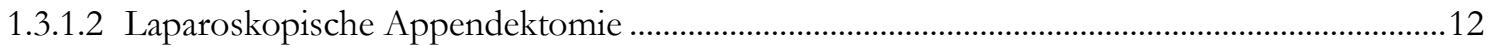

1.3.2 Konservative Therapieoptionen ………………….............................................................13

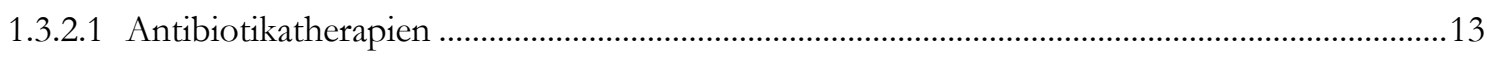

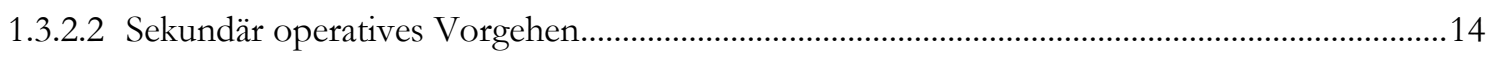

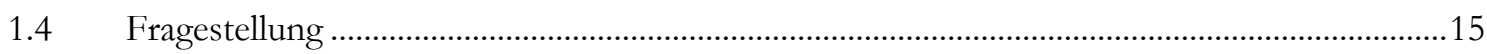

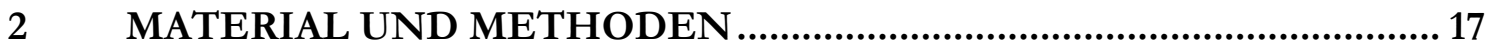

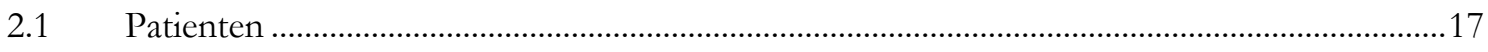

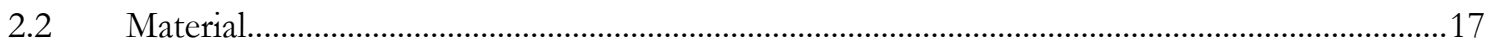

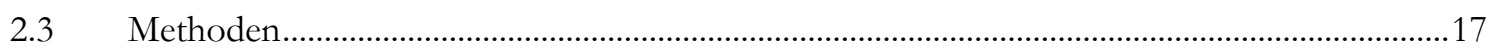

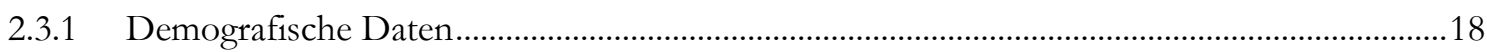

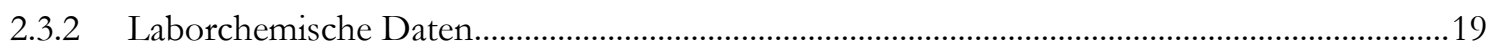

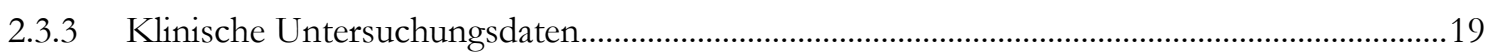


3 ERGEBNISSE 20

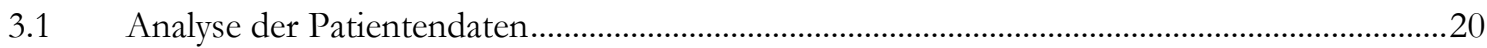

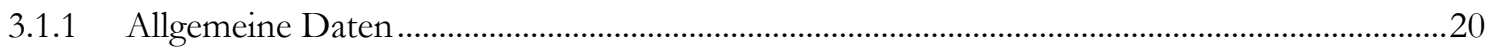

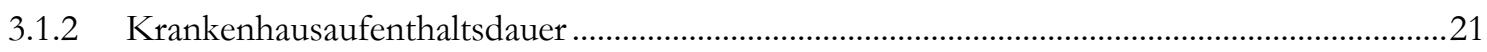

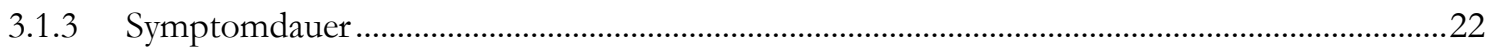

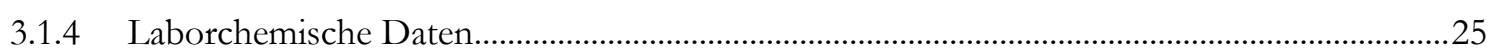

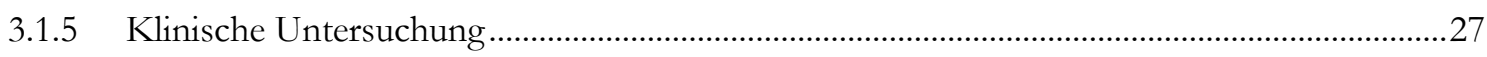

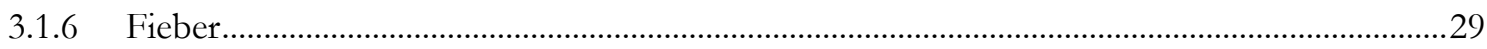

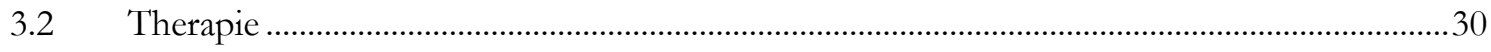

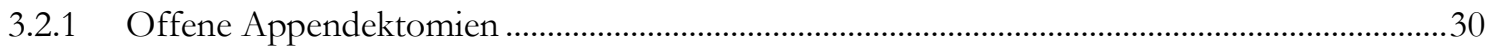

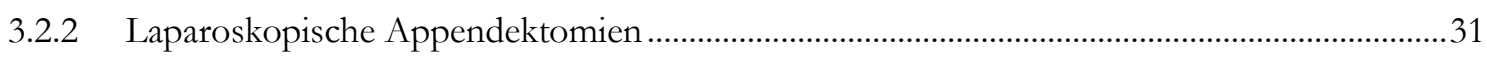

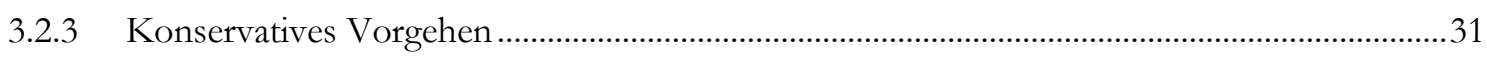

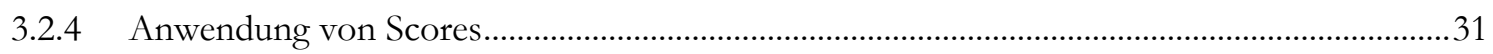

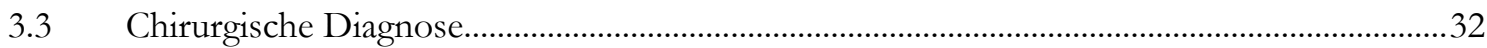

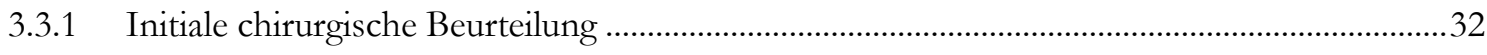

3.3.2 Wechsel der Diagnose von unkomplizierter zu komplizierter Appendizitis ............................33

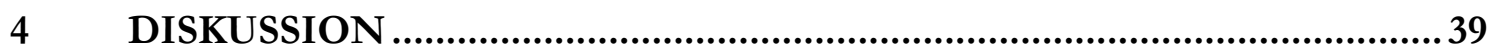

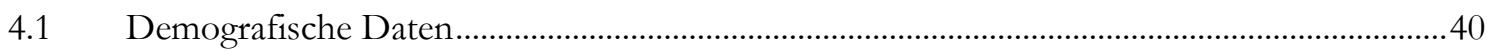

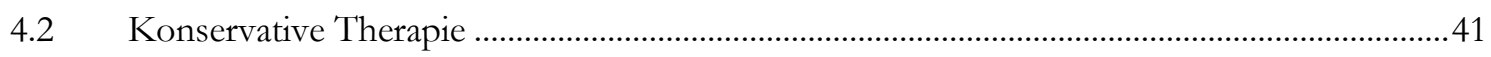

4.3 Laborchemische Daten und therapeutische Konsequenz ..........................................................4

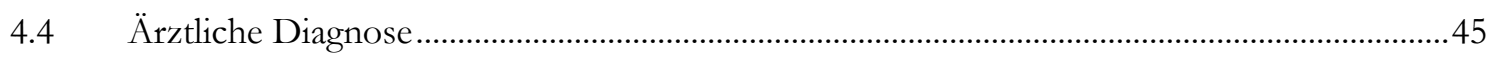

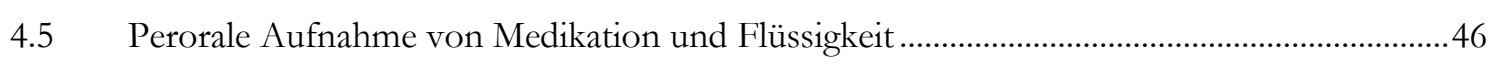

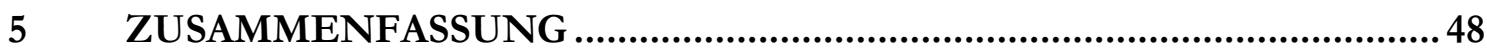

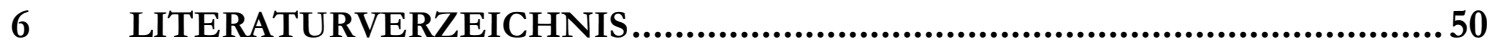




\section{ABBILDUNGSVERZEICHNIS}

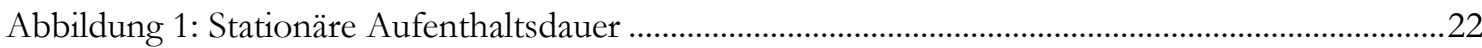

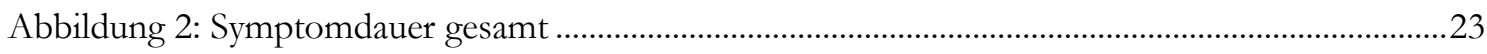

Abbildung 3: Symptomdauer perforierter Appendizitiden ................................................................24

Abbildung 4: Symptomdauer gedeckt-perforierter Appendizitiden.........................................................2

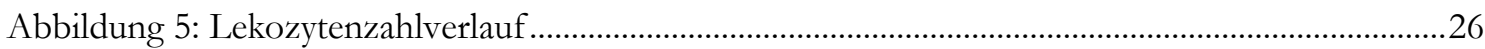

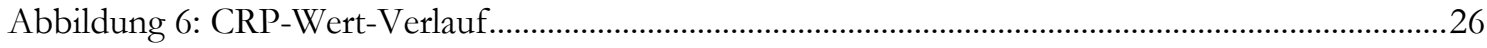

Abbildung 7: Histologische Ergebnisse bei klassischen Zeichen einer Appendizitis............................28

Abbildung 8: Histologische Ergebnisse bei nicht-klassischen Zeichen einer Appendizitis ................29

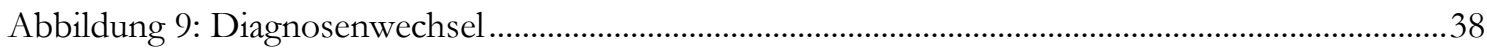

\section{TABELLENVERZEICHNIS}

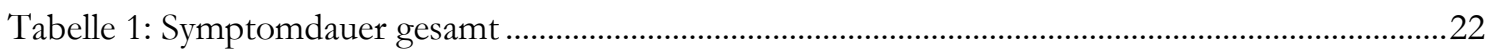

Tabelle 2: Symptomdauer perforierter Appendizitiden....................................................................23

Tabelle 3: Symptomdauer gedeckt-perforierter Appendizitiden............................................................24

Tabelle 4: Histologie der offenen Appendektomien.................................................................................

Tabelle 5: Histologie der laparoskopischen Appendektomien..................................................................

\section{ABKÜRZUNGSVERZEICHNIS}

CRP: $\quad$ C-reaktives Protein

ESBL: $\quad$ Extended spectrum beta-lactamase 


\section{EINLEITUNG}

\subsection{Allgemeines}

Die akute Appendizitis ist eines der häufigsten chirurgischen Krankheitsbilder und ist die häufigste Indikation zu einer Notfalloperation in Deutschland. Jährlich werden in Deutschland zwischen 127.000 und 135.000 Appendektomien durchgeführt (Kronman 2016, Nolting et al. 2011).

Die Appendizitis ist die häufigste Ursache für die Diagnose eines akuten Abdomens und tritt in westlichen Ländern mit einer Inzidenz von 100 Erkrankungen pro 100.000 Menschen pro Jahr auf (Nolting et al. 2011).

Laut Angaben des statistischen Bundesamtes wurden im Jahr 2014 allein bei der Patientengruppe der unter 14-Jährigen 17.675 (9.240 männlich, 8.435 weiblich) Appendektomien durchgeführt (Statistisches Bundesamt 2015).

Die initiale Diagnose bzw. der Verdacht auf eine Appendizitis werden auch von niedergelassenen Ärzten (Allgemeinmedizinern, Internisten, Gynäkologen) gestellt und es wird meist daraufhin eine Einweisung in ein entsprechendes Krankenhaus veranlasst. Dort werden weitere Untersuchungen wie laborchemische Untersuchungen, Abdomensonografie, klinische Untersuchung und Computertomografien des Abdomens zur Bestätigung bzw. zum Ausschluss einer akuten Appendizitis durchgeführt.

Für das weitere Vorgehen entscheidend ist es dann, ob eine unkomplizierte oder komplizierte Appendizitis vorliegt.

Als komplizierte Appendizitis wird das Vorliegen von Abszedierung, Perforation oder Peritonitis zusätzlich zu der eigentlichen Appendizitis verstanden.

Weiterhin wird hierbei noch eine akute Appendizitis mit generalisierter Peritonitis oder eine akute Appendizitis mit lokaler Peritonitis unterschieden.

Es ist unumstritten, dass eine akute komplizierte Appendizitis operiert werden muss (Panknin 2015).

Allerdings stellt sich die Frage, ob jede unkomplizierte Appendizitis einer operativen Therapie bedarf, oder ob hier ein konservatives Vorgehen mit Abwarten, klinischer 
Beobachtung, dem Auswerten von Laborparametern und bildgebenden Verfahren, sowie gegebenenfalls Antibiotikatherapien gerechtfertigt ist.

Es stellt sich weiterhin die Frage, ob die konservative Therapie einer unkomplizierten Appendizitis nicht das schonendere Vorgehen für den Patienten darstellt und inwiefern eine primär konservative Therapie ein gegebenenfalls sekundäres operatives Vorgehen beeinflusst.

In der Studie von Paulina Salminen aus dem Universitätsklinikum von Turku, Finnland wurden im Zeitraum von 2009 bis 2012272 Patienten mit einer akuten Appendizitis appendektomiert (Salminen et al. 2015).

23 dieser Patienten (8,4\%) klagten nach diesem Eingriff im Verlauf über weitere Beschwerden, wie Bauchschmerzen oder Störungen der Magen-Darm-Funktion, die vermutlich auf das Vorliegen von postoperativen Adhäsionen im Bauchraum zurückzuführen waren. Einer dieser Patienten musste aufgrund von Adhäsionen nachoperiert werden, bei einem weiteren trat eine Hernie an der Appendektomienarbe auf, die ebenfalls operiert werden musste. Zusätzlich klagten insgesamt 14\% der in dieser Studie operierten Patienten nach Ablauf eines Jahres immer noch über abdominelle Beschwerden (Salminen et al. 2015).

Auch vor diesem Hintergrund ist die primäre operative Therapie einer unkomplizierten Appendizitis nicht immer ein harmloser Eingriff und muss sicher kritisch gesehen werden. In der Diagnostik der akuten Appendizitis sind heutzutage bildgebende Verfahren wie Abdomensonografie und die Computertomografie des Abdomens ein wichtiger Baustein. Hierbei ist der Durchmesser der Appendix das entscheidende Kriterium. Beträgt der Durchmesser mehr als sechs Millimeter gilt dies als Hinweis für eine Appendizitis.

$\mathrm{Zu}$ erwähnen ist hierbei, dass sowohl bei der Abdomensonografie als auch bei der Computertomografie des Abdomens der gleiche Wert für den Durchmesser angegeben wird, wobei es bei der Messung per Abdomensonografie Abweichungen von ein bis zwei Millimetern gibt (Orscheln und Trout 2015) und somit die Abdomensonografie als alleiniges diagnostisches Verfahren nicht ausreichend ist.

Bei der Computertomografie des Abdomens muss auch in Anbetracht des meist jungen Lebensalters der Patienten die Strahlenbelastung berücksichtigt werden. Laut einer Arbeit von Nekolla et al (2017) beträgt die durchschnittliche medizinische Strahlenbelastung für 
Menschen in Deutschland jedes Jahr etwa 1,5 Milli-Sievert (mSv) (für das Jahr 2012) durch natürliche Strahlenquellen, zum Beispiel durch kosmische oder Erd-Strahlung. Bei einer Computertomografie des Abdomens liegt die Dosis bei mindestens acht und bis zu $20 \mathrm{mSv}$ (Nekolla et al. 2017).

Der Hauptanteil der zivilisatorischen Strahlenbelastung wird durch die Medizin und hier durch Computertomografien verursacht (Nekolla et al. 2017).

Bei einer von 2000 Computertomografien des Abdomens treten somatische Auswirkungen allein durch die Strahlenexposition auf (Panknin 2015).

Somit ist die Computertomografie zwar ein wichtiges und genaues Verfahren zur Diagnose einer Appendizitis und zur Unterscheidung von unkomplizierter und komplizierter Form, sollte aber ebenfalls nicht sorglos eingesetzt werden.

Unklar ist, ob bei nicht diagnostizierter komplizierter Appendizitis eine primäre konservative Therapie mit Abwarten, Schmerztherapie und abführenden Maßnahmen sowie gegebenenfalls einer Antibiotikatherapie zu vertreten ist und wie bei Kindern verfahren werden soll (Panknin 2015).

Auch vor dem Hintergrund, dass der erste Verdacht auf das Vorliegen einer Appendizitis häufig in den Praxen niedergelassener Ärzte gestellt wird, ist bisher nicht geklärt, inwieweit ein primär konservatives Vorgehen mit Beobachten, Abdomensonografie, Labor und bei entsprechenden Umständen eine Antibiotikatherapie vertretbar wäre.

Hier spielt sicher die individuelle Ausstattung einer Praxis sowie die Erfahrung des ambulanten Behandlers die entscheidende Rolle.

Wenn man davon ausgeht, dass bei dem Verdacht auf eine Appendizitis ohne Vorliegen eines akuten Abdomens, also bei einer nicht komplizierten Appendizitis, ein abwartendes Verhalten und eine Antibiotikatherapie vertretbar wäre, also eine Hospitalisation nicht zwingend notwendig wäre, hätte dies auch Auswirkungen für die Sozioökonomie.

Insbesondere die Anzahl an apparativen Diagnostiken (z. B. mittels Computertomografie des Abdomens) und explorativen Operationen sowie negativen Appendektomien sollte zum einen im Sinne des Patienten, zum anderen auch aus Kostengründen so gering wie möglich gehalten werden. 


\subsection{Appendizitis}

\subsubsection{Pathophysiologie}

Die Appendizitis ist ein eigenständiges Krankheitsbild, das die isolierte Entzündung des Appendix vermiformis beschreibt. Sie ist die häufigste Darmentzündung und weist ohne Geschlechtsbevorzugung eine Morbidität von 5/1000 Menschen pro Jahr auf. Ihr Häufigkeitsgipfel liegt zwischen dem 20. und 30. Lebensjahr.

Pathogenetisch sind am Zustandekommen dieser Entzündung Darmentleerungsstörungen durch Kotsteine (Koprolithen), Fremdkörper wie Pflanzensamen und Parasiten (z.B. Oxyuren, Madenwürmer, Spulwürmer), Narbenstenosen, Lageveränderungen der Appendix vermiformis, lymphatische Hyperplasien und Tumoren verantwortlich.

Folge einer Entleerungsstörung sind dann bakterielle Infektionen der im Darm anwesenden Bakterien wie Enterokokken und Escherichia coli. Die Appendizitis verläuft morphologisch in mehreren Stadien, die einer zeitlichen Abfolge unterworfen sind. Sie beginnt nach ca. sechs Stunden mit der Appendizitis erosiva, die mit einer Rötung der Serosa und einer Schleimhauterosion einhergeht.

Danach folgt nach ca. 12 Stunden die Appendizitis phlegmonosa, bei der sich das entzündliche Infiltrat transmural ausbreitet und die gesamte Appendix vermiformis betrifft. Nach ca. 24 Stunden folgt die Appendizitis ulcerophlegmonosa, bei welcher multiple Schleimhautulzerationen entstehen, die Serosa mit Fibrinbelägen überzogen ist und die Mukosa zugrunde geht.

Nach ca. 48 Stunden entstehen durch die Entzündung bedingt Mikroinfarkte, die intramurale Abszesse nach sich ziehen; dieses Stadium wird als Appendizitis ulcerophlegmonosa et abscedens bezeichnet.

Letztlich folgt nach ca. 72 Stunden das Stadium der Appendizitis gangraenosa, bei dem durch die Gewebeeinschmelzung eine Infektion mit Fäulniserregern geschieht. Makroskopisch ist die Appendix vermiformis nun schwarzrot. Die Entzündung greift nun auf umliegendes Gewebe über. Als häufigste Komplikation bei einer nicht rechtzeitig behandelten Appendizitis kommt es zu einer Perforation und der konsekutiven Peritonitis

Des Weiteren kann es infolge von durch Entzündung verursachten Verwachsungen zu einem Bridenileus kommen. Nur im ersten Stadium, der Appendizitis erosiva ist eine 
vollständige Ausheilung möglich, bei allen weiteren Stadien gibt es nur noch eine Defektheilung (Riede et al. 2001).

Klinisch wird die Appendizitis in eine nicht-komplizierte und eine komplizierte Form unterschieden. Bei der nicht-komplizierten Form handelt es sich um die isolierte Entzündung des Appendix vermiformis ohne das Hinzutreten von weiteren Entzündungen oder anderen Komplikationen wie Perforation, Peritonitis oder peritonealer Phlegmone.

Im Umkehrschluss ist also eine komplizierte Appendizitis eine, bei der die o.g. oder auch noch weitere Komplikationen (perihepatischer Abszess, Sepsis) hinzutreten.

Bereits 1959 veröffentlichte Coldrey eine Studie mit 471 Patienten, die mit einer nichtkomplizierten Appendizitis konservativ mit Antibiotika behandelt wurden.

Seither gab es weitere kontrollierte und randomisierte Studien (Hansson et al 2009, Styrud et al 2006, Vons et al 2011), die zeigten, dass bei einer nicht-komplizierten Appendizitis eine antibiotische Therapie ebenso effektiv und sicher sein kann wie ein operatives Vorgehen mit einer Appendektomie (Kim et al 2015, Coldrey 1956, Hansson et al 2009, Styrud et al 2006, Vons et al 2011).

Es konnten bisher jedoch keine prädiktiven Faktoren evaluiert werden, die eine sichere Entscheidung rechtfertigen, ob man eine Appendizitis nun konservativ oder operativ behandeln muss.

\subsubsection{Klinische Untersuchung}

Die Diagnosestellung einer Appendizitis ist nicht allein von der klinischen Untersuchung abhängig, allerdings gibt es bei der klinischen Untersuchung bereits Zeichen, die ausreichen, eine Operationsindikation zu stellen und eine weitere Diagnostik überflüssig machen (Löhnert 2017). Hierzu zählt z.B. das Vorliegen eines Peritonismus.

Es gibt jedoch keinen körperlichen Untersuchungsbefund mit der man eine Appendizitis zweifelsfrei bestätigen oder ausschließen kann. Dennoch gibt es eine Reihe von anamnestischen und klinischen Hinweisen, welche bei der Diagnosestellung hilfreich sind (Montali und von Flüe 2008).

An erster Stelle steht wie bei nahezu allen Erkrankungen die Anamnese. 
Die Patienten klagen häufig über initial periumbilicale Bauchschmerzen, die sich im Verlauf in den rechten Unterbauch verlagern. Hinzutreten können Fieber bis 39,0 Grad Celsius, Übelkeit, Brechreiz und Erbrechen sowie das Sistieren des Stuhlgangs. Bei einer retrozökalen Appendizitis kann es zu einer Entzündung des Urethers kommen, welche mit einer Erythrozyturie und Leukozyturie einhergeht, wobei man hierbei nicht die Diagnose einer Appendizitis zu Gunsten eines Harnwegsinfektes verwerfen sollte.

Des Weiteren kann es zu einer rektal-axillären Temperaturdifferenz von ca. einem Grad Celsius kommen, wobei in Studien hierfür keine Bedeutung für die Diagnosestellung dieser Untersuchung herausgearbeitet werden konnte (Putzki und Reichert 1988).

Es gibt einer Reihe von Tests, die dem Untersucher zur Verfügung stehen, um Hinweise auf das Vorliegen einer Appendizitis zu sammeln, die hier im Folgenden aufgeführt werden. Alle diese Tests einschließlich der rektal-axillären Temperaturmessung lassen sich einfach und in jeder Praxis durchführen.

Bei der Palpitation des Abdomens gibt es den Mc-Burney-Punkt im lateralen Drittel der Linie zwischen Bauchnabel und Spina iliaca anterior superior (so genannte Monro-Linie), der bei einer Appendizitis druckdolent ist.

Die Linie zwischen beiden Spina iliacae wird als Lenzmann-Linie bezeichnet. Im rechtslateralen Drittel befindet sich der Lanz-Sonnenburg-Punkt, der ebenfalls bei einer Appendizitis auf Druck schmerzen kann.

Rechts periumbilical befindet sich der Morris-Punkt.

Der kontralaterale Loslassschmerz, also bei tiefer Palpitation des linken Unterbauches und folgendem Loslassen wird ein Schmerz im rechten Unterbauch induziert, wird als BlumbergZeichen benannt.

Weiterhin kann es zu Schmerzen bei Erschütterung und zu Schmerzen bei der rektaldigitalen Untersuchung (Douglas-Schmerz) kommen. Das retrograde Ausstreichen des Colons in Richtung Coecum wird Rovsing-Zeichen genannt; das Ausstreichen etwa vom McBurney-Punkt in Richtung Appendix wird als Bassler-Zeichen bezeichnet.

Das Anheben des rechten Beines gegen Widerstand ist das Psoas-Zeichen. Hierbei wird der Musculus Psoas durch die Appendizitis gereizt, was zu einer nur unter Schmerzen durchführbaren Kontraktion führt. 
Das Ben-Asher Zeichen ist dann positiv, wenn bei tiefer Palpitation nach cranialwärts im linken Oberbauch auf einen Hustenstoß des Patienten Schmerzen im rechten Unterbauch auslösbar sind.

Bei einer spontan eingetretenen Schmerzfreiheit des Patienten kann dies Ausdruck einer stattgehabten Perforation sein.

\subsubsection{Labor-Untersuchungen}

Bei der Diagnosestellung einer Appendizitis werden routinemäßig Laborparameter zum Nachweis einer Entzündungsreaktion im Körper bestimmt. Unabhängig vom Nutzen der Laborparameter zur Diagnose bzw. Ausschluss einer Erkrankung werden routinemässig auch die üblichen präoperativen Werte (wie z.B. Blutgerinnungswerte) bestimmt.

Des Weiteren dienen Laborparameter zur Detektion anderer Erkrankungen, welche sich durch ähnliche Symptome wie eine Appendizitis äußern können. Es sollten deshalb nicht nur Blutbild und CRP (C-reaktives Protein), sondern auch Leberwerte zur Diagnose von Gallenwegs- oder Lebererkrankungen, Amylase und Lipase zur Untersuchung auf eine Pankreatitis sowie eine Urinuntersuchung zur Detektion einer Urolithiasis oder Harnwegsinfektion bestimmt werden.

Wie bereits unter 1.2.2 erwähnt kann aber auch die Appendizitis eine Erythrozyturie und Leukozyturie verursachen. Entscheidend für das weitere Vorgehen ist dann das Zusammenspiel von klinischer Untersuchung und der Bewertung der ergänzenden Diagnostik wie Laborwerte und bildgebenden Verfahren.

\subsubsection{Modifizierter Alvarado-Score}

Es existieren mehrere Punkte-Systeme zur Identifizierung einer akuten Appendizitis. Das Ziel dieser Systeme ist es, die Zahl unnötiger Untersuchungen (wie z.B. die Computertomografie des Abdomens) zu reduzieren, die negative Appendektomierate (also 
die Durchführung einer Appendektomie ohne das Vorliegen einer Appendizitis; zwischen neun und 40\%) (Meltzer et al. 2013) zu reduzieren und auch die beste Therapie für den Patienten zu finden.

Beim modifizierten Alvarado-Score wird für jedes der folgenden Symptome je ein Punkt vergeben: Schmerzmigration auf die rechte untere Bauchseite; Essstörung; Übelkeit und Erbrechen; Loslassschmerz; Fieber. Für Druckschmerz im rechten Unterbauch und für eine Leukozytose gibt es jeweils 2 Punkte.

Laut Score-Interpretation schließt ein Alvarado-Score-Ergebnis $<3-4$ Punkten eine akute Appendizitis relativ sicher aus (Meltzer et al. 2013).

Der Score reicht von Null bis zu zehn Punkten. Für die beiden laut Score wichtigsten Faktoren (Leukozytose und Schmerzen im rechten Unterbauch) vergibt der Score je zwei Punkte. Bei einem Ergebnis von ein bis drei Punkten sieht der Score keinen weiteren Handlungsbedarf. Bei einem Ergebnis von vier bis sieben Punkten empfiehlt der Score eine weitere Beobachtung und eine klinische Kontrolle nach sechs Stunden. Bei einem Ergebnis von sieben bis zehn Punkten wird ein operatives Vorgehen empfohlen.

Mehrere Untersuchungen konnten jedoch die Effizienz dieses Scores nicht belegen. Es wurde in einer Studie von Schorr mit 266 Patienten gezeigt, dass zwar die negative Appendektomierate von 20 auf 9,3\% gesenkt werden konnte, allerdings wurden auch bei zehn Patienten Punktwerte von eins bis drei erreicht, die an einer Appendizitis (eine davon perforiert) litten. 140 Patienten wurden gemäß Score sofort operiert, 126 Patienten mit eins bis sechs Punkten wurden entgegen dem Score sofort operiert, worunter sich neun mit initial perforierter Appendizitis befanden (Schorr et al. 2000).

In der Studie von Meltzer et al. 2013 waren insgesamt 261 Patienten (von 18 bis 89 Jahre, mittleres Alter 35) mit Verdacht auf akute Appendizitis involviert. Von diesen Patienten hatten zum Schluss lediglich 53 (20\%) tatsächlich eine akute Appendizitis.

Der modifizierte Alvarado-Score hatte eine Sensitivität von $72 \%$ und eine Spezifität von lediglich 54\%. Dagegen konnten die Chirurgen die klinische Diagnose mit einer Sensitivität von 93\% und Spezifität von 33\% stellen (Meltzer et al. 2013).

Somit konnte die Effizienz des modifizierten Alvarado-Score nicht belegt werden. 


\subsubsection{AIR - Score}

Der AIR-Score (Appendicitis Inflammatory Response Score) vergibt für das Vorliegen der folgenden Symptome die in Klammern dahinter stehenden Punkte; Erbrechen (1); Schmerzen in der rechten Fossa iliaca (1); Loslassschmerz leicht (1), moderat (2), stark (3); Temperatur über $38.5^{\circ} \mathrm{C}$ (1); Leukozyten [x10/1] 10-14.9 (1), über 15 (2); Anteil an polymorphkernigen Leukozyten $70 \%$ bis $84 \%$ (1), mehr als 85\% 82); C-reaktives Protein [mg/l] 10 bis 49 (1), über 50 (2). Patienten mit null bis vier Punkten gelten als Niedrig-Risiko, mit fünf bis acht Punkten als Intermediär-Risiko und solche mit neun oder mehr Punkten als Hoch-Risiko-Gruppe (Andersson und Andersson 2008).

Scott et al. 2015 untersuchte 464 Patienten, die mit dem Verdacht auf eine Appendizitis in die Klinik kamen.

Bei diesen Patienten wurde der AIR-Score erhoben, jedoch ohne das Ergebnis des Scores den behandelnden Chirurgen mitzuteilen.

Bei 332 Patienten (71,6\%) wurde letztendlich eine Entzündung der Appendix vermiformis ausgeschlossen, davon bei 84 (18,1\%) Patienten allerdings erst nach explorativer Operation. Von den 132 Patienten mit bestätigter Appendizitis hatten 51 (10,9\%) ein fortgeschrittenes Stadium der Erkrankung.

„Ein AIR-Score von mindestens fünf Punkten, entsprechend einem mittleren bis zu einem hohen Risiko, entdeckte eine Appendizitis mit einer Sensitivität von 90\%, fortgeschrittene Stadien sogar mit einer Sensitivität von 98\%. Die Spezifizität, also der Anteil der korrekt erkannten Patienten ohne Appendizitis, betrug 63\%; der negative prädiktive Wert lag damit bei 94\%. Erreichte der AIR - Score mindestens neun Punkte, lag die Spezifität bei 97\%.

Bei den meisten Appendizitispatienten war es bereits zu einer Perforation oder Gangrän gekommen“ (Schumacher 2015).

Allerdings hatten selbst in der Hochrisikogruppe 23\% der Patienten keine Appendizitis.

Durch einen AIR-Score unter fünf Punkten wurden 63\%der Patienten, die keine Appendizitis hatten, korrekt identifiziert (Andersson und Andersson 2008).

AJ Scott und seine Kollegen empfehlen nach dieser Studie, Patienten, die in dem Score mit einem niedrigen Risiko für das Vorliegen einer Appendizitis stratifiziert wurden, zunächst wieder aus der Klinik zu entlassen und zu instruieren bei Beschwerdepersistenz oder progredienz wieder vorstellig zu werden. 
Ist dann bei der Reevaluation ein mittleres Risiko festzustellen, sollte eine Sonografie erfolgen. Bei positivem Befund wird operiert. Bei negativem oder unklarem Befund sollte eine Computertomografie des Abdomens erfolgen, um den Befund zu klären.

Bei der Feststellung eines hohen Risikos für das Vorliegen einer Appendizitis kann direkt operiert werden, oder präoperativ zur Sicherung der Diagnose eine Computertomografie des Abdomens erfolgen.

Auch vom Kostenfaktor spielt der AIR-Score vermutlich eine Rolle; in einer Stichprobe der Studie von Scott et al. (2015) konnte die Quote der negativen operativen Explorationen von $39 \%$ auf 23\% gesenkt werden (Schumacher 2015; Scott et al. 2015).

\subsubsection{Sonografie des Abdomens bei Verdacht auf Appendizitis}

Die Abdomensonografie stellt ein wichtiges, in Deutschland flächendeckend und auch im ambulanten Bereich vorhandenes und für den Patienten harmloses Diagnostikverfahren dar. Sowohl in der Computertomografie des Abdomens, wie auch in der Abdomensonografie werden die gleichen Maßstäbe eingesetzt. Eine Vergrößerung des Durchmessers der Appendix von mehr als sechs Millimeter wird als diagnostischer Hinweis auf das Vorliegen einer Appendizitis angesehen. Allerdings ist die Messung dieses Durchmessers per Computertomografie meist größer als die Messung per Abdomensonografie (1,3-1,4mm bei einer nicht - entzündeten Appendix) versus 2,0 mm beim Vorliegen einer Appendizitis (Orscheln und Trout 2015).

Es kann bei einer Abdomensonografie auch zu anatomischen Überlagerungen kommen oder $\mathrm{zu}$ anatomischen Varianten, die eine sichere Diagnose mittels Ultraschalluntersuchung erschweren. In solchen Fällen, stellt eine ergänzende computertomografische Untersuchung einen weiterführenden diagnostischen Baustein dar (O’Malley et al. 2015, Birnbaum und Wilson 2000). 


\subsubsection{Computertomografie des Abdomens bei Verdacht auf Appendizitis}

Sind körperliche Untersuchung, Anamnese, Labor und Sonografie nicht ausreichend zur sicheren Diagnose bzw. Ausschluss einer Appendizitis oder einer anderen akuten abdominalen Erkrankung, ist es sinnvoll eine weitere Bildgebung des Abdomens anzufertigen, um über das weitere Vorgehen entscheiden zu können.

Eine Abdomen Computertomografie sollte und wird auch nicht als Standard oder Routine bei isoliertem Verdacht auf eine Appendizitis eingesetzt.

Wie vorab schon erwähnt sollte aufgrund der Strahlenbelastung und der damit verbundenen teils schweren Nebenwirkungen eine Computertomografie nicht sorglos eingesetzt werden. Bereits im Jahr 2007 bzw. 2009 wurden Studien publiziert, die vor sorglosem Einsatz von Computertomografien warnten. Amy Berrington postulierte, dass etwa 29.000 Krebserkrankungen in den USA im Jahr 2007 (bei insgesamt annähernd 70.000.000 durchgeführten Computertomografien) durch Computertomografien verursacht sein könnten (Berrington 2009).

Als Pathophysiologie werden hierbei Schäden durch Röntgenstrahlung an der DNA genannt (Brenner und Hall 2007).

\subsubsection{Differentialdiagnosen zu einer Appendizitis}

Differentialdiagnostisch muss bei dem Verdacht auf das Vorliegen einer Appendizitis an eine Vielzahl von Erkrankungen gedacht werden. Angefangen von Harnwegsinfektionen, einfachen Obstipationen, muskuloskelettalen Erkrankungen, bis hin $\mathrm{zu}$ schweren Krankheiten wie chronisch entzündlichen Darmerkrankungen, Stoffwechselstörungen (z.B. Porphyrie) und Tumoren. Das Herausarbeiten und Deuten der einzelnen Symptome und das Einleiten eventueller weiterer diagnostischer Schritte ist entscheidend vom Untersucher und dessen Erfahrung abhängig. 


\subsection{Therapiemöglichkeiten}

\subsubsection{Operative Verfahren}

Die Indikation zu einem operativen Vorgehen hängt von der Anamnese, der klinischen Untersuchung, gegebenenfalls den Laborparametern und den bildgebenden Verfahren ab. Besteht der dringende Verdacht auf eine komplizierte Appendizitis muss unbestritten operiert werden.

\subsubsection{Offene Appendektomie}

Heutzutage wird die offene Appendektomie nur bei zu erwartenden Komplikationen oder komplizierten Verläufen einer laparoskopisch begonnenen Appendektomie durchgeführt. $\mathrm{Zu}$ erwartende Komplikationen sind zum Beispiel stark ausgeprägte Verwachsungen bei bereits häufig operierten Patienten oder das Vorhandensein von größeren Abszessen oder eine ausgeprägte Peritonitis, die eine intraabdominelle Lavage wahrscheinlich werden lässt.

\subsubsection{Laparoskopische Appendektomie}

Die laparoskopische Appendektomie ist die derzeit favorisierte Therapie (Çiftçi 2015). Gegenüber der offenen Operationsweise hat dieses minimal - invasive Vorgehen die Vorteile, dass es weniger Wundinfektionen gibt, die Schmerzen der Patienten postoperativ geringer sind und die Hospitalisierungsdauer geringer ist.

Des Weiteren bietet die Laparoskopie einen diagnostischen Vorteil, da der gesamte Bauchraum durch den Operateur in Augenschein genommen werden kann. Eine finnische Studie von Kotaluoto analysierte die Mortalität im Zeitraum von 30 Tagen nach laparoskopischer Appendektomie im Zeitraum von 1990 bis 2010. Die Mortalitätsrate betrug 2,1/1000. Die Mortalität war in der Patientengruppe der über 60jährigen erhöht (Kotaluoto et al. 2016). 
Die Laparoskopie ist derzeit besonders bei weiblichen Patienten die favorisierte Operationsmethode, da sie eine umfassendere Abklärung von differentialdiagnostischen Krankheitsbildern erlaubt.

\subsubsection{Konservative Therapieoptionen}

Die konservative Therapie von unkomplizierten und sogar auch komplizierten Appendizitiden ist Thema vieler Veröffentlichungen und beschäftigt die Medizin seit Jahrzehnten. Bis heute unklar sind einheitliche Verfahren oder Standards, wie eine konservative Therapie optimal ist.

Maßnahmen wie Bettruhe, Nahrungskarenz, Flüssigkeitssubstitution, abführende Maßnahmen und Antibiotikatherapien neben einer selbstverständlichen adäquaten Analgesie stehen zur Verfügung. Eine einheitliche Evidenz hierzu gibt es bisher nicht. Auch gibt es bisher in Deutschland keine einheitliche Leitlinie zur Therapie einer Appendizitis (Salminen et al. 2015, Ehlers et al. 2016).

Eine retrospektive Studie aus Taiwan über den Zeitraum von 2000 bis 2010 analysierte 239.821 Patienten, die mit der Diagnose Appendizitis in Krankenhäusern behandelt wurden. $12.235(5,1 \%)$ wurden konservativ behandelt. Von diesen 12.235 Patienten wurden 864 (also 7,1\%) doch noch appendektomiert. (Liang et al. 2016) In Umkehrung konnten also 11.313 Patienten (92,9\%) der Patienten erfolgreich konservativ behandelt werden.

\subsubsection{Antibiotikatherapien}

Eine im Oktober 2016 von Rollins veröffentlichte Meta-Analyse postulierte, dass Antibiotika verordnet werden müssen, sobald der Verdacht oder die Diagnose einer Appendizitis gestellt werde (Rollins et al. 2016).

In dieser Studie wurden 1430 Patientendaten ausgewertet. 727 davon wurden antibiotisch behandelt, 703 wurden appendektomiert. 123 der initial antibiotisch behandelten Patienten mussten letztlich doch operiert werden. Eine erhöhte Komplikationsrate im Vergleich zu der Gruppe, der initial operierten gab es nicht (Rollins et al. 2016). 
Der Arbeitskreis für Krankenhaushygiene der deutschen Gesellschaft für Chirurgie empfiehlt bei einer Appendizitis die Antibiotika Metronidazol, Clindamycin und Gentamycin als perioperative Behandlung (Abele-Horn 2014; Knebel et al. 2011).

Bei einer Divertikulitis, also einer sehr ähnlichen Erkrankung wie die Appendizitis wird in der Leitlinie eine perorale oder je nach klinischem Status des jeweiligen Patienten intravenöse Gabe von Ciprofloxacin und Metronidazol (neben Cefuroxim, Moxifloxacin, Ampicillin/Sulbactam und Piperacillin/Tazobactam) empfohlen. (Leifeld et al. 2014)

Eine Studie von Kronman aus dem Juli 2016 verglich in einer Studie mit 24.984 Patienten Piperacillin (in Kombination oder auch ohne Tazobactam), Ticarcillin (in Kombination oder auch ohne Clavulansäure), Ceftazidim, Cefepim und Carbapenemen.

Alle Patienten waren appendektomiert worden. 7330 dieser Patienten litten an einer komplizierten Appendizitis. Hierbei gab es keine signifikanten Unterschiede zwischen einer erweiterten Antibiose mit Carbapenemen oder einer herkömmlichen Antibiose mit $\beta$ Laktam-Antibiotika und Makroliden (Kronman 2016).

Allerdings waren die Patienten in dieser Studie zwischen drei und 18 Jahren alt und wurden alle appendektomiert. Inwiefern sich diese Daten auf Erwachsene und vor allem auf nicht operierte Patienten anwenden lässt, bleibt offen.

\subsubsection{Sekundär operatives Vorgehen}

Wie unter 1.3.2.1 bereits erwähnt, gibt es derzeit keine Hinweise, dass ein sekundäres operatives Vorgehen nach vorausgegangener konservativer Therapie ein erhöhtes Risiko für die Patienten darstellt (Rollins et al. 2016).

Insofern erscheint es vernünftig bei dem Verdacht auf eine Appendizitis vorerst einen konservativen Therapieansatz zu verfolgen und erst nach Ausschöpfung der zur Verfügung stehenden konservativen Therapieoptionen ein operatives Vorgehen zu favorisieren. 


\subsection{Fragestellung}

Es ist derzeit unumstritten, dass eine komplizierte Appendizitis operativ versorgt werden muss.

In dieser Arbeit sollen retrospektiv Patientendaten ausgewertet werden, um weitere Evidenz für oder auch gegen ein konservatives Vorgehen bei einer unkomplizierten Appendizitis zu sammeln.

Es ist unklar, ob jede unkomplizierte Appendizitis operiert werden sollte oder ob nicht ein konservatives Vorgehen gerechtfertigt ist.

Weiterhin ist unklar, wie genau ein konservatives Vorgehen bemessen sein muss.

Es gibt keine Hinweise, dass ein initial konservatives Vorgehen Nachteile für ein sekundär operatives Vorgehen birgt.

Bisher konnte jedoch nicht bewiesen werden, dass ein konservatives Vorgehen dem operativen von Vorteil ist.

Es konnte aber auch keine signifikante Überlegenheit der Operation gezeigt werden.

Diese Thesen sollen nachfolgend beantwortet werden.

1. Eine unkomplizierte Appendizitis sollte nach adäquater Diagnostik und unter engmaschiger ärztlicher Kontrolle konservativ behandelt werden. Entwickelt sich im Verlauf aus einer unkomplizierten eine komplizierte Appendizitis besteht eine Operationsindikation.

2. Führt eine konservative Therapie nicht zur Heilung, so birgt eine primär konservative Therapie kein erhöhtes Risiko und keine erhöhte Komplikationsrate für eine sekundär durchgeführte Operation.

3. Der CRP-Wert sowie die Leukozytenanzahl haben für die Operationsindikation keinen prädiktiven Wert. Sie können jedoch zu differentialdiagnostischen Überlegungen, als Verlaufskontrolle und zum Beweis eines Therapieerfolges herangezogen werden.

4. Die ärztliche Untersuchung und Diagnosesicherheit sind entscheidend. Wie hoch ist die Diagnosesicherheit in der ärztlichen Diagnostik einer Appendizitis? 
5. Die perorale Aufnahme von Flüssigkeiten und Medikationen sind unbedingte Vorrausetzungen für die konservative Therapie einer unkomplizierten Appendizitis.

6. Da es ab einem Lebensalter von über 60 Jahren nach aktueller Literatur (Kotaluoto et al. 2016) zu einer erhöhten Mortalität auch bei laparoskopischen Appendektomien kommt, sollte für diese Patientengruppe insbesondere eine konservative Therapie angestrebt werden. 


\section{MATERIAL UND METHODEN}

\subsection{Patienten}

Das Patientenkollektiv besteht aus den Patienten mit der Diagnose Appendizitis, die im Zeitraum von 2012 bis 2015 in den Agaplesion-Diakoniekliniken Kassel behandelt wurden.

\subsection{Material}

Zur Datenerhebung wurden die allgemeinchirurgischen Krankenakten der Patienten der Agaplesion - Diakoniekliniken Kassel aus dem Zeitraum von 2012 bis 2015 retrospektiv analysiert. Den Patienten wurden Nummern zugeordnet, die eine anonymisierte Auswertung erlaubten.

\subsection{Methoden}

Die gesammelten Daten wurden in einer Excel-Tabelle zusammengetragen und mit Hilfe dieses Programms ausgewertet.

Folgende Daten wurden dabei erhoben: Patientennummer, Geburtsdatum, Geschlecht, Alter zum Zeitpunkt der Behandlung, Symptombeginn, klinischer Untersuchungsbefund, Zeichen einer Appendizitis (Mc Burney, Psoas-Zeichen, Blumberg-Zeichen, Fieber), die Anzahl der chirurgischen Untersuchungen, die initiale Leukozytenzahl im Blutbild und die Leukozytenzahl im Blutbild bei Entlassung, der initiale CRP-Wert und der CRP-Wert bei Entlassung, die Krankenhaus-Aufenthaltsdauer, ob eine konservative oder operative Therapie durchgeführt wurde, die Operationsart (offen oder laparoskopisch), das Ergebnis der Histologie, ob eine perforierte oder nicht-perforierte Appendizitis vorlag, ob eine komplizierte oder nicht komplizierte Appendizitis vorlag, ob eine Sonografie des 
Abdomens durchgeführt wurde und mit welchem Ergebnis, ob eine Computertomografie des Abdomens durchgeführt wurde und mit welchem Ergebnis.

Des Weiteren wurde untersucht, ob die initiale chirurgische Beurteilung mit dem endgültigen histologisch gesicherten Ergebnis übereinstimmte und ob die Diagnose im Verlauf zwischen unkomplizierter und komplizierter Appendizitis gewechselt wurde.

Um diese Daten zu kategorisieren wurden Gruppen erstellt. Der Symptombeginn wurde in folgende Gruppen unterteilt; Symptombeginn weniger als zwölf Stunden, zwischen zwölf und 24 Stunden, zwischen 24 und 48 Stunden, mehr als 48 Stunden und chronischrezidivierende Beschwerden.

Da die Dokumentation in den Akten sehr unterschiedlich war bezüglich der untersuchten Zeichen einer Appendizitis, wurde hierbei zwischen dem Vorliegen von klassischen Zeichen einer Appendizitis bzw. deren Abwesenheit unterschieden.

Ferner wurde die Beziehung zwischen dem Vorliegen einer histologisch gesicherten Perforation bzw. gedeckten Perforation und der Symptomdauer untersucht.

Bei den Laborparametern wurden Leukozytenzahl und der CRP-Wert untersucht, wobei hier die Werte bei Aufnahme und, sofern im Klinikaufenthalt bestimmt, bei Entlassung analysiert wurden.

Die histologischen Beschreibungen zeigten ebenso wie die Dokumentation der klinischen Untersuchung gewisse Unterschiede, sodass auch hier die Patientendaten in Gruppen unterteilt wurden. Es wurde unterschieden zwischen histologisch negativem Ergebnis (also Appendixpräparat ohne entzündliche Veränderungen), nicht entzündlichen Appendixformen (Kotsteine, Lipomatose, neurogene Appendikopathie) und positiven Befunde (also eindeutig entzündlich veränderte Appendizitiden), wobei hier auch zwischen perforiert und nicht-perforiert unterschieden wurde.

\subsubsection{Demografische Daten}

In die Erfassung wurden der Name der Patienten, das Geburtsdatum, das Alter der Patienten zum Zeitpunkt der Behandlung und die Krankenhausaufenthaltsdauer einbezogen. 


\subsubsection{Laborchemische Daten}

Bei allen Patienten wurde standardmäßig ein Blutbild erstellt und der CRP-Wert bestimmt und in die Datenaufnahme mit einbezogen. Andere Laborwerte wie Leberwerte, Gerinnungswerte oder speziellere Werte wie Procalcitonin wurden nicht bei allen Patienten bestimmt und eigneten sich somit nicht für eine aussagekräftige Auswertung. Bei zwei Patienten wurde ein Procalcitonin bestimmt, was eine intensivmedizinische Behandlung zur Folge hatte.

\subsubsection{Klinische Untersuchungsdaten}

Die in den Patientenakten dokumentierten Anamnesen, Sonografiebefunde und gegebenenfalls Computertomografiebefunde wurden in die Auswertung aufgenommen. Hierbei gab es jedoch große Unterschiede, was eine einheitliche Bewertung schwierig machte. Somit wurden wie bereits oben erwähnt Gruppen gebildet, um eine Kategorisierung zu ermöglichen. Der Symptombeginn wurde in Gruppen zu kürzer als zwölf Stunden, zwischen zwölf und 24 Stunden, zwischen 24 und 48 Stunden, länger als 48 Stunden und chronisch rezidivierend eingeteilt.

Die dokumentierten körperlichen Untersuchungsbefunde variierten ebenso stark, sodass hier eine Unterteilung zwischen dem Vorliegen von klassischen Appendizitissymptomen und deren Abwesenheit erfolgte. Bei den Sonografiebefunden erfolgte die Einteilung in unauffällig, das Vorliegen einer pathologischen Kokarde oder das Vorliegen von freier intraabdomineller Flüssigkeit.

Weiterhin wurde untersucht, ob die initiale Beurteilung anhand der klinischen Untersuchung mit der letztlich histologisch gesicherten Diagnose übereinstimmte oder nicht, also die Treffsicherheit der klinischen Untersuchung analysiert. 


\section{ERGEBNISSE}

\subsection{Analyse der Patientendaten}

\subsubsection{Allgemeine Daten}

Das Patientenkollektiv umfasste 152 Patienten, 104 weibliche und 48 männliche. Die Patienten waren bei Aufnahme in die Klinik zwischen 12 und 78 Jahren alt (Median 29). 18 Patienten (11,8\%) waren über 60 Jahre alt. 99 der Patienten wiesen klassische Appendizitiszeichen auf und 53 wiesen atypische Symptome auf.

Ein Patient (Patientennummer 52) wurde initial internistisch mit einer Addisonkrise behandelt und im stationären Verlauf bei sonografisch gesehener freier Flüssigkeit im Abdomen wurde eine diagnostische Laparoskopie durchgeführt, wobei sich eine Appendizitis zeigte.

Ein Patient (Patientennummer 78) verstarb im stationären Aufenthalt an den Folgen einer Infarktpneumonie und Sepsis, wobei dieser Patient an multiplen Vorerkrankungen (schwere COPD, Herzinsuffizienz, Adipositas) litt und es bei ihm zu einem sehr komplizierten Verlauf mit Wundheilungsstörungen, der Entwicklung eines Platzbauches und mehrfachen ReLaparotomien und abdominellen Lavagen kam.

Ein Patient (Patientennummer neun) wurde aus einem Kreiskrankenhaus mit einer generalisierten Vier-Quadranten-Peritonitis verlegt. Ursächlich hierfür zeigte sich eine Appendizitis mit perityphlitischem Abszess.

Drei Patientinnen wurden initial von niedergelassenen Gynäkologen gesehen und von dort wurde eine Krankenhauseinweisung mit dem Verdacht auf Appendizitis veranlasst.

Zwei Patientinnen wurden erst in einer gynäkologischen Klinik untersucht und dort wurde eine chirurgische Übernahme veranlasst.

Zehn Patienten wurden von Hausärzten eingewiesen, elf Patienten wurden initial internistisch untersucht und nach chirurgischem Konsil in die chirurgische Abteilung der Klinik übernommen und zwei Patienten wurden von niedergelassenen Chirurgen eingewiesen. 
Eine Patientin (Patientennummer 86) litt seit zwei Wochen an diffusen Unterbauchbeschwerden und wurde erst von einem niedergelassenen Gynäkologen, dann auch stationär gynäkologisch mit einer Antibiose bei Verdacht auf Salpingitis behandelt, bei ausbleibender Besserung erfolgte letztlich die chirurgische Übernahme und laparoskopische Appendektomie mit dem histologischen Ergebnis ,katarrhalische Appendizitis“.

Eine weitere Patientin (Patientennummer 97) befand sich zuvor sechs Tage lang in stationär gynäkologischer Behandlung und wurde dort entlassen, bevor sie sich selbst auf der Notaufnahme der Agaplesion-Diakonieklinik vorstellte.

Bei einer Patientin (Patientennummer 129) bestanden chronisch-rezidivierende Unterbauchschmerzen, die zuerst ambulant, dann stationär bei dem Verdacht auf eine Adnexitis behandelt wurden, bei ausbleibender Besserung erfolgte schließlich eine diagnostische Laparoskopie, bei welcher eine Appendizitis entdeckt wurde.

\subsubsection{Krankenhausaufenthaltsdauer}

Die 152 Patienten dieses Kollektivs wurden zwischen einem und 29 Tagen aufgrund einer Appendizitis bzw. deren Folgen oder auch aufgrund von Komplikationen stationär behandelt. Der Mittelwert der Aufenthaltsdauer des gesamten Patientenkollektivs lag bei 5,65 Tagen, der Median bei fünf Tagen.

Die vier Patienten, welche konservativ versorgt wurden, waren zwischen einem und vier Tagen stationär behandelt worden. Der Mittelwert lag hier bei 2,25, der Median bei 2,5 Tagen. 


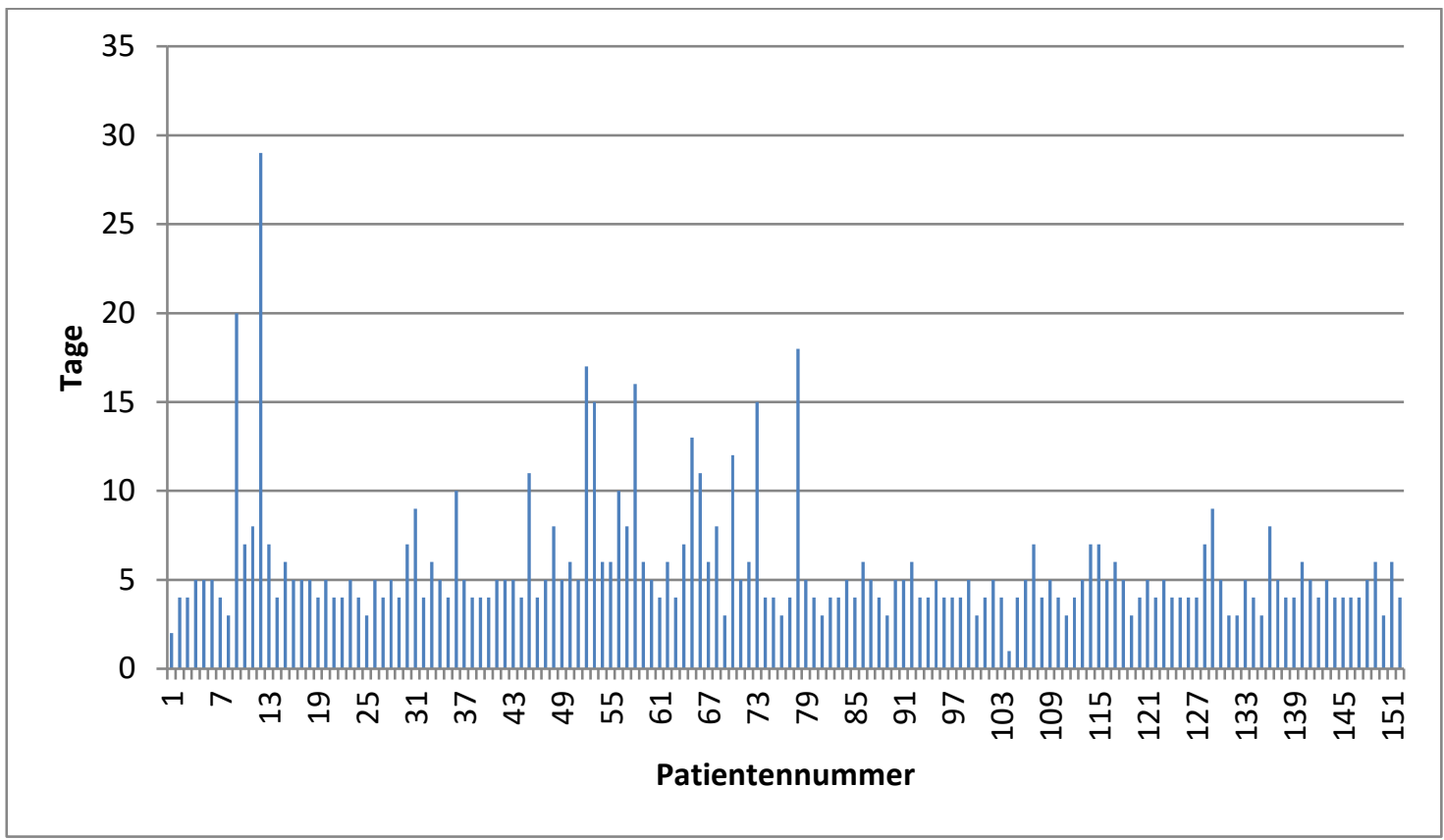

Abbildung 1: Stationäre Aufenthaltsdauer

\subsubsection{Symptomdauer}

Die Patienten wurden anhand der Symptomdauer in fünf Gruppen unterteilt, wobei die Patienten der ersten Gruppe seit maximal zwölf Stunden Beschwerden aufwiesen, die der zweiten Gruppe zwischen zwölf und 24 Stunden Beschwerden hatten, die der dritten Gruppe zwischen 24 und 48 Stunden Beschwerden geäußert hatten und die der vierten Gruppe seit mehr als 48 Stunden über Beschwerden klagten.

Weiterhin wurden die Patienten mit chronisch-rezidivierenden Beschwerden in einer Gruppe zusammengefasst.

Tabelle 1: Symptomdauer gesamt

\begin{tabular}{|l|l|l|l|l|l|}
\hline Symptomdauer & $\begin{array}{l}\text { bis zu 12 } \\
\text { Stunden }\end{array}$ & $\begin{array}{l}12 \text { bis 24 } \\
\text { Stunden }\end{array}$ & $\begin{array}{l}\text { bis 48 } \\
\text { Stunden }\end{array}$ & $\begin{array}{l}\text { mehr als 48 } \\
\text { Stunden }\end{array}$ & $\begin{array}{l}\text { chronisch- } \\
\text { rezidivierend }\end{array}$ \\
\hline $\begin{array}{l}\text { Anzahl der } \\
\text { Patienten }\end{array}$ & 32 & 30 & 9 & 69 & 12 \\
\hline
\end{tabular}




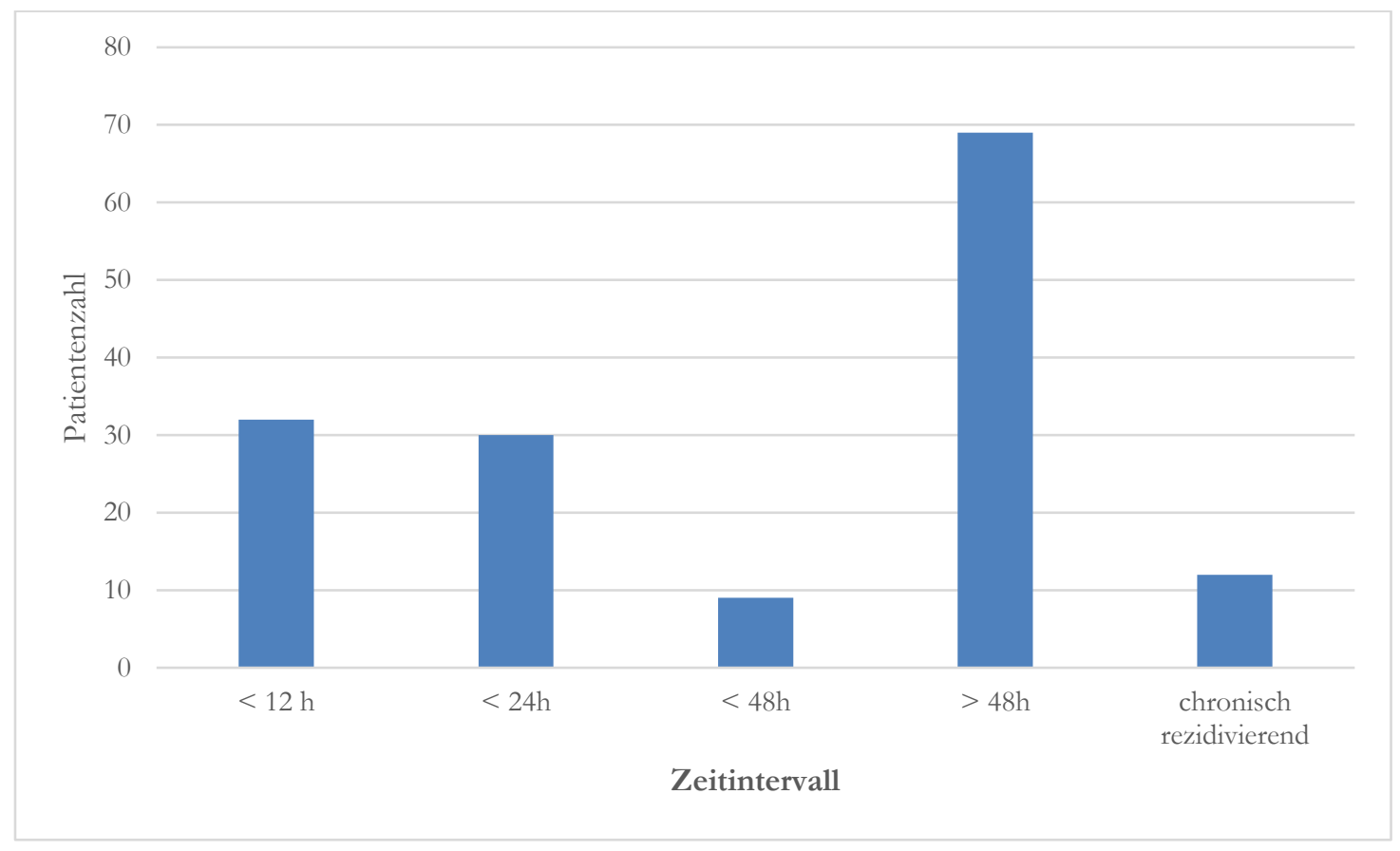

Abbildung 2: Symptomdauer gesamt

Bei den Patienten mit einer perforierten bzw. gedeckt perforierten Appendizitis wurde die gleiche Einteilung nochmals vorgenommen. Es gab in dem Patientenkollektiv 48 perforierte und elf gedeckt perforierte Appendizitiden.

Tabelle 2: Symptomdauer perforierter Appendizitiden

\begin{tabular}{|l|l|l|l|l|l|}
\hline Symptomdauer & $\begin{array}{l}\text { bis zu 12 } \\
\text { Stunden }\end{array}$ & $\begin{array}{l}12 \text { bis 24 } \\
\text { Stunden }\end{array}$ & $\begin{array}{l}24 \text { bis } 48 \\
\text { Stunden }\end{array}$ & $\begin{array}{l}\text { mehr als 48 } \\
\text { Stunden }\end{array}$ & $\begin{array}{l}\text { chronisch- } \\
\text { rezidivierend }\end{array}$ \\
\hline $\begin{array}{l}\text { Anzahl der } \\
\text { Patienten }\end{array}$ & 12 & 16 & 3 & 17 & 1 \\
\hline
\end{tabular}




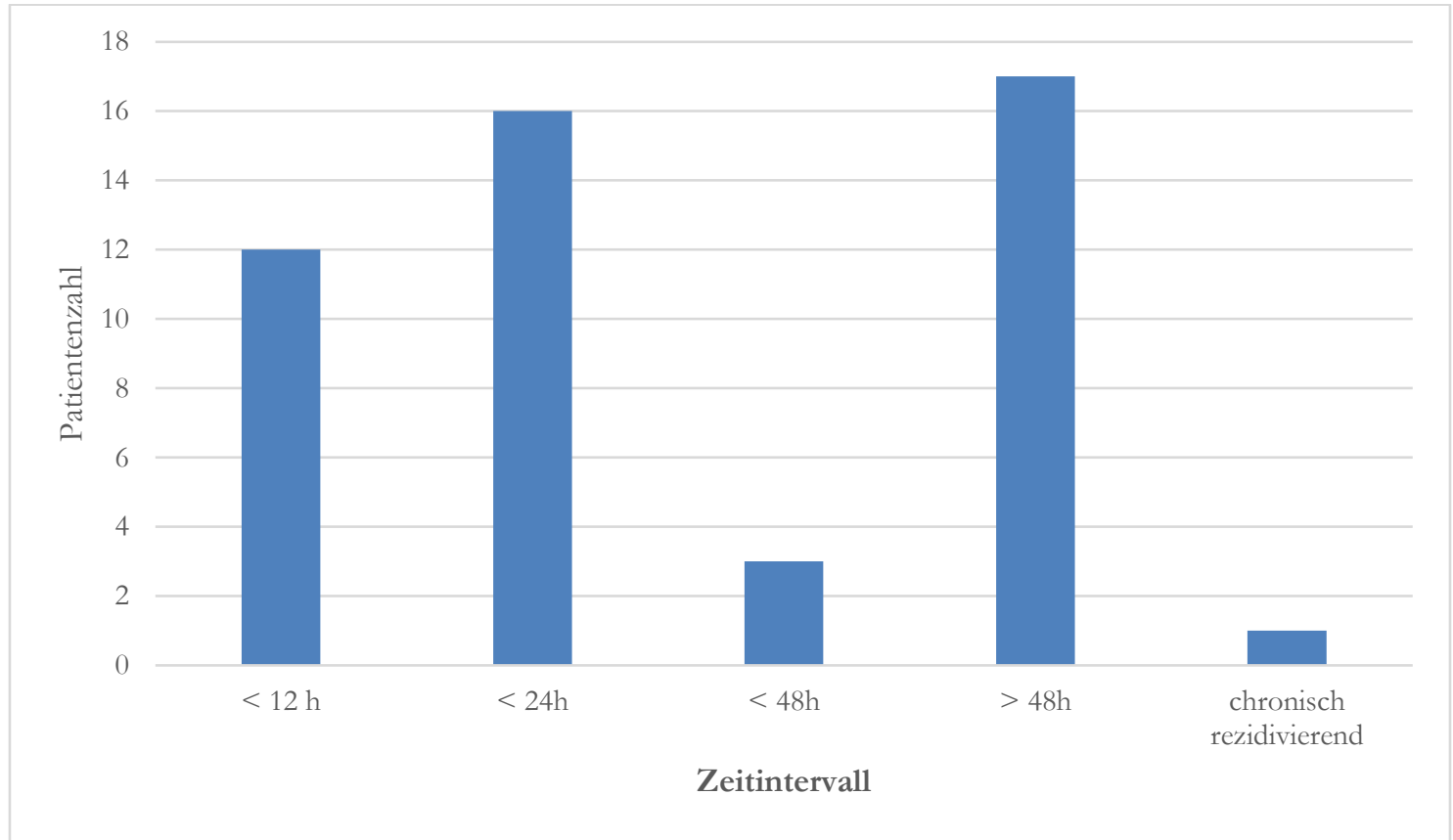

Abbildung 3: Symptomdauer perforierter Appendizitiden

Tabelle 3: Symptomdauer gedeckt-perforierter Appendizitiden

\begin{tabular}{|l|l|l|l|l|l|}
\hline Symptomdauer & $\begin{array}{l}\text { bis zu 12 } \\
\text { Stunden }\end{array}$ & $\begin{array}{l}12 \text { bis 24 } \\
\text { Stunden }\end{array}$ & $\begin{array}{l}24 \text { bis } 48 \\
\text { Stunden }\end{array}$ & $\begin{array}{l}\text { mehr als 48 } \\
\text { Stunden }\end{array}$ & $\begin{array}{l}\text { chronisch- } \\
\text { rezidivierend }\end{array}$ \\
\hline $\begin{array}{l}\text { Anzahl der } \\
\text { Patienten }\end{array}$ & 1 & 2 & 1 & 6 & 1 \\
\hline
\end{tabular}




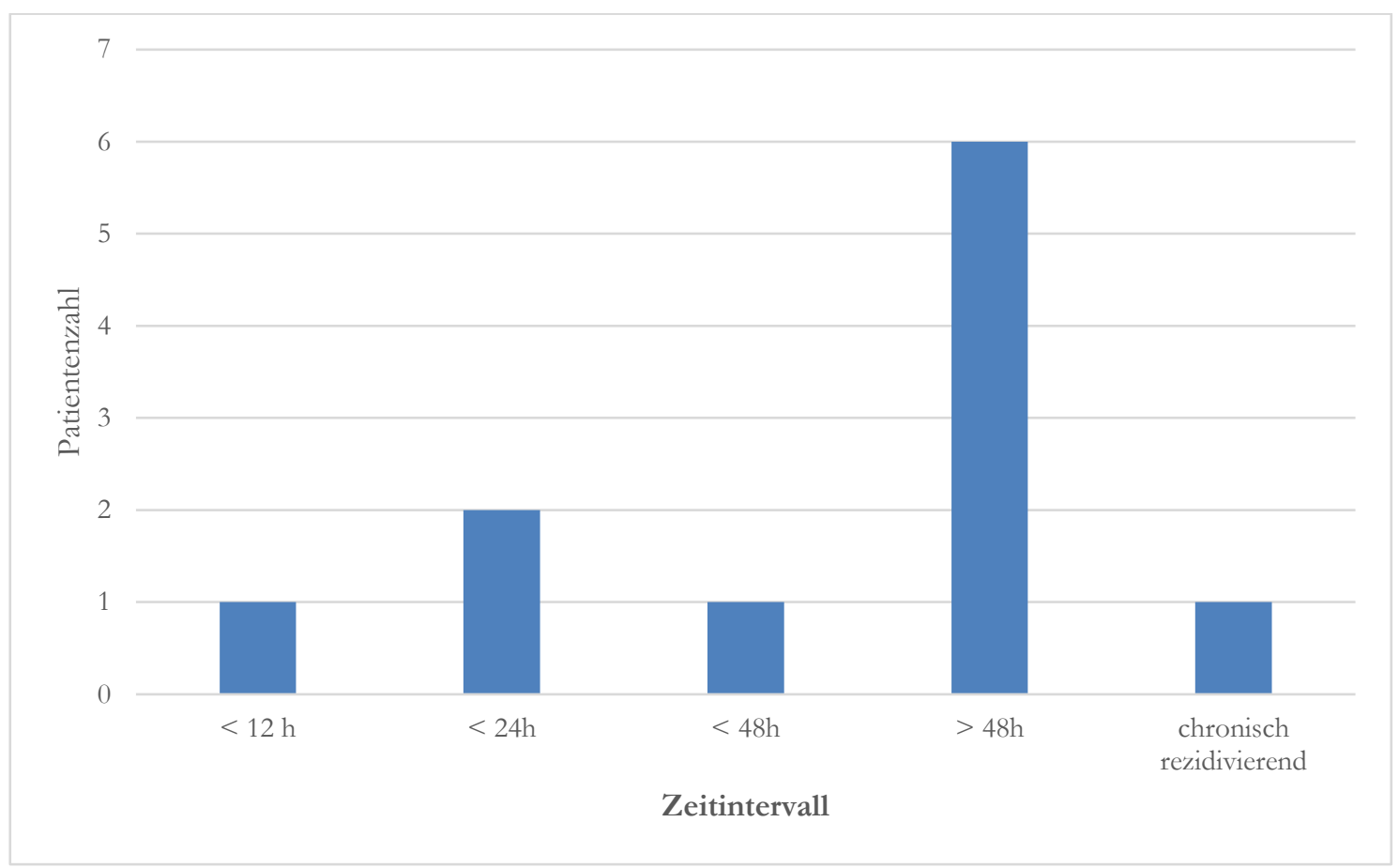

Abbildung 4: Symptomdauer gedeckt-perforierter Appendizitiden

\subsubsection{Laborchemische Daten}

Bis auf eine Patientin (Patientennummer 132) wurden bei allen Patienten ein Blutbild und der CRP-Wert initial bestimmt. Relevant war bei dem Blutbild die Leukozytenzahl. Diese lag

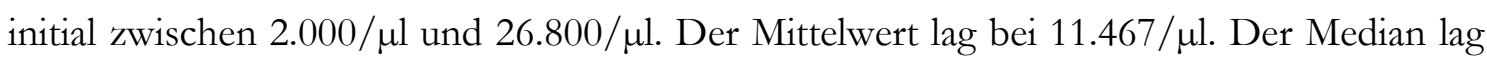
bei $11.100 / \mu l$.

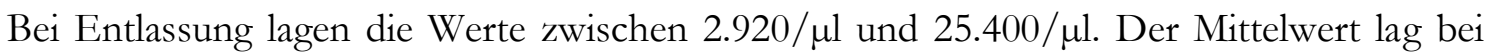
7.254/ $\mu$ l. Der Median lag bei $6.400 / \mu 1$.

Der CRP-Wert wurde in $\mathrm{mg} / \mathrm{dl}$ gemessen. Der Normwert ist mit $<0,5 \mathrm{mg} / \mathrm{dl}$ definiert.

Bei 21 Patienten wurden nur initial Blutbild und CRP-Wert bestimmt, sodass bei diesen Patienten eine Aussage über die Verlaufswerte nicht möglich ist. Hinweise, dass die laborchemischen Untersuchungen bei diesen Patienten therapeutische Konsequenz gehabt haben, fanden sich nicht. 


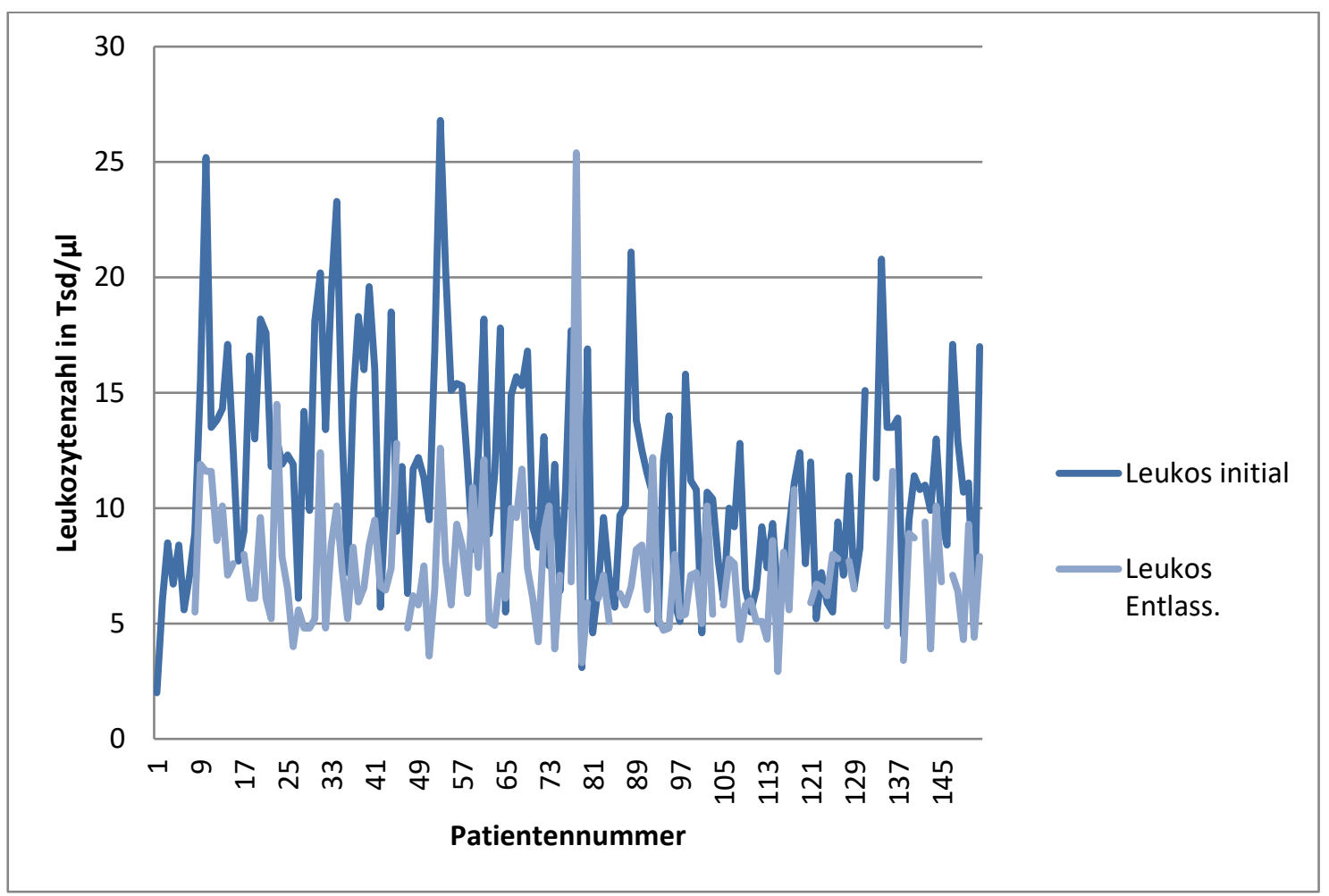

Abbildung 5: Leukozytenzahlverlauf

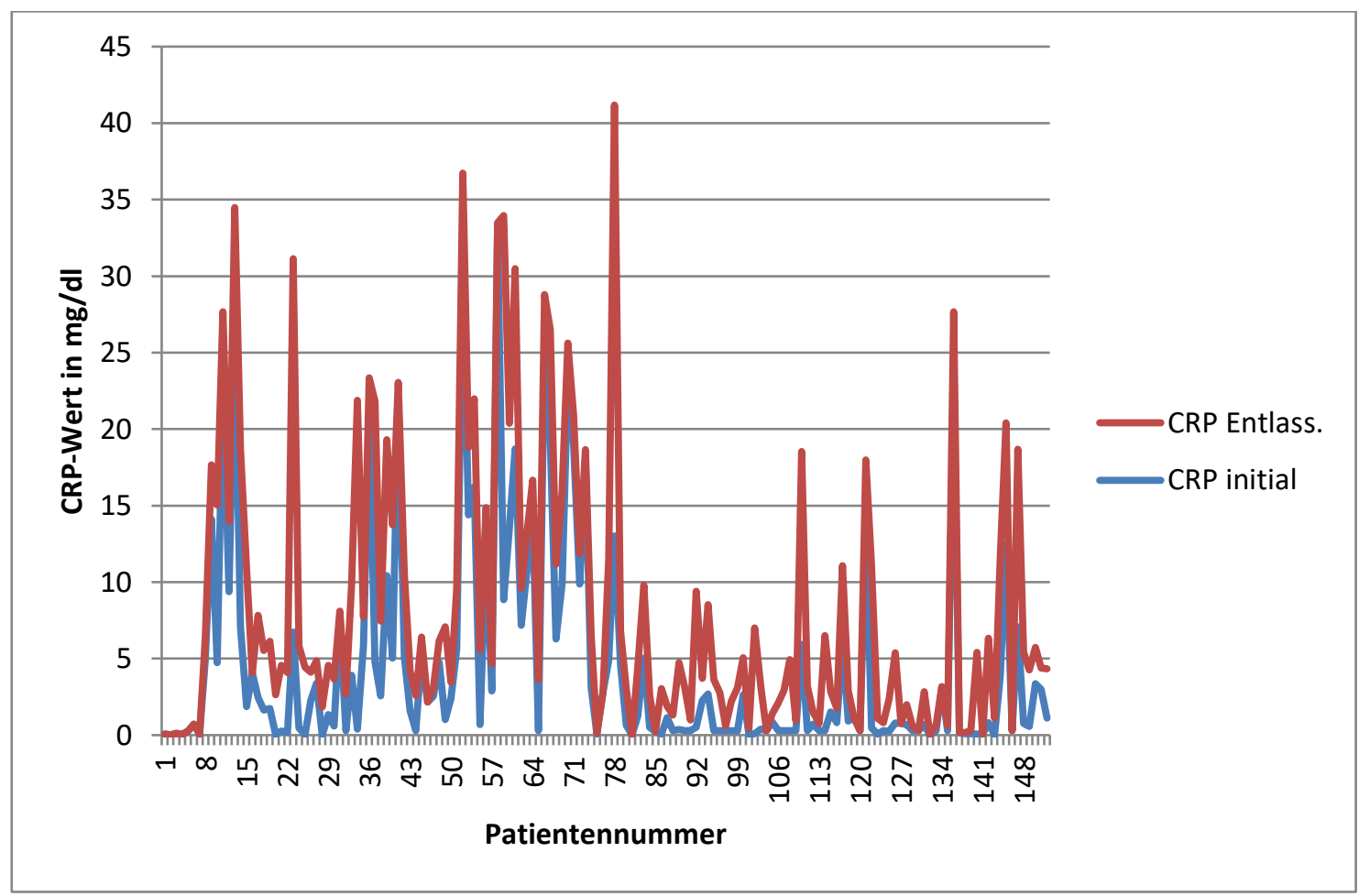

Abbildung 6: CRP-Wert-Verlauf 
Es konnte bis auf bei einer Patientin weder bei der Leukozytenzahl, noch bei den ermittelten CRP-Werten eine Korrelation zwischen den gemessenen Werten und dem weiteren Vorgehen gefunden werden. Vielmehr entscheidend für das therapeutische Vorgehen war der klinische Status des jeweiligen Patienten.

Durchschnittlich lagen die Leukozytenzahlen bei Entlassung niedriger als bei der Aufnahme. Die absoluten Werte hatten jedoch keinen Einfluss auf die Entlassung und wurden von Klinikseite auch nicht weiterverfolgt.

Lediglich bei einer Patientin (Patientennummer 20) erfolgte bei steigenden Entzündungsparametern die Indikation zur diagnostischen Laparoskopie, wobei sich eine Appendizitis zeigte, die histologisch bestätigt werden konnte. Allerdings lagen bei dieser Patientin auch im Verlauf klassische Zeichen einer Appendizitis vor.

Die Analyse von Leukozytenzahl und CRP-Wert hatte bei unseren Patienten also bei 0,65\% (einer Patientin) therapeutische Konsequenz.

\subsubsection{Klinische Untersuchung}

Die Dokumentation der jeweiligen klinischen Untersuchungen in den Akten differierte in den vorliegenden Akten stark, sodass die Unterscheidung zwischen dem Vorliegen von klassischen bzw. typischen Appendizitiszeichen gegenüber deren Abwesenheit erfolgen musste. Bei 99 Patienten bestanden klassische Zeichen einer Appendizitis, bei 53 fehlten diese.

Bei den 99 Patienten mit klassischen Appendizitiszeichen wurden drei nicht operiert und konservativ behandelt, 83 zeigten ein histologisch positives Präparat, zwei waren histologisch negativ und elf Patienten zeigten im histologischen Präparat keine entzündlichen Veränderungen.

Bei den 53 Patienten ohne klassische Appendizitiszeichen wurde einer nicht operiert und konservativ behandelt, 46 zeigten histologische Präparate mit eindeutig entzündlichen Veränderungen, bei einem Patienten zeigte sich ein unauffälliger Appendix und bei sechs Patienten zeigten sich nicht entzündliche Veränderungen.

Bei 45 Patienten wurde keine Sonografie durchgeführt, 42 davon wurden operiert.

Bei diesen 42 Patienten zeigte das histologische Ergebnis, dass 32 histologische Präparate eindeutig entzündliche Veränderungen aufwiesen und zehn nicht entzündlich verändert waren. 
Bei zehn Patienten wurden Computertomografien durchgeführt. Bei einem Patienten (Patientennummer 58) erfolgte eine Computertomografie bei dem Verdacht auf ein Leberhämangiom, wobei dann eine gedeckt perforierte Appendizitis diagnostiziert wurde, die sich histologisch bestätigte.

Eine Patientin (Patientennummer 5) zeigte in der Computertomografie einen unauffälligen Befund, wurde konsiliarisch durch die Internisten der Klinik mittels Ösophagogastroduodenoskopie und Coloskopie untersucht, wobei hier keine wegweisende Pathologie (außer einer dezenten Antrumgastritis) gefunden werden konnte und sich schließlich bei Beschwerdepersistenz und langer Beschwerdedauer (länger als zwei Wochen) für eine Appendektomie entschieden wurde. Das histologische Ergebnis zeigte einen nicht entzündlich veränderten Appendix. Nicht zu eruieren war hierbei, ob die Beschwerden der Patientin nach dem stationären Aufenthalt dauerhaft nicht mehr auftraten.

Bei den übrigen acht Patienten, bei welchen eine Computertomografie durchgeführt worden war, zeigten sich eindeutig entzündliche Veränderungen der Appendix im histologischen Präparat.

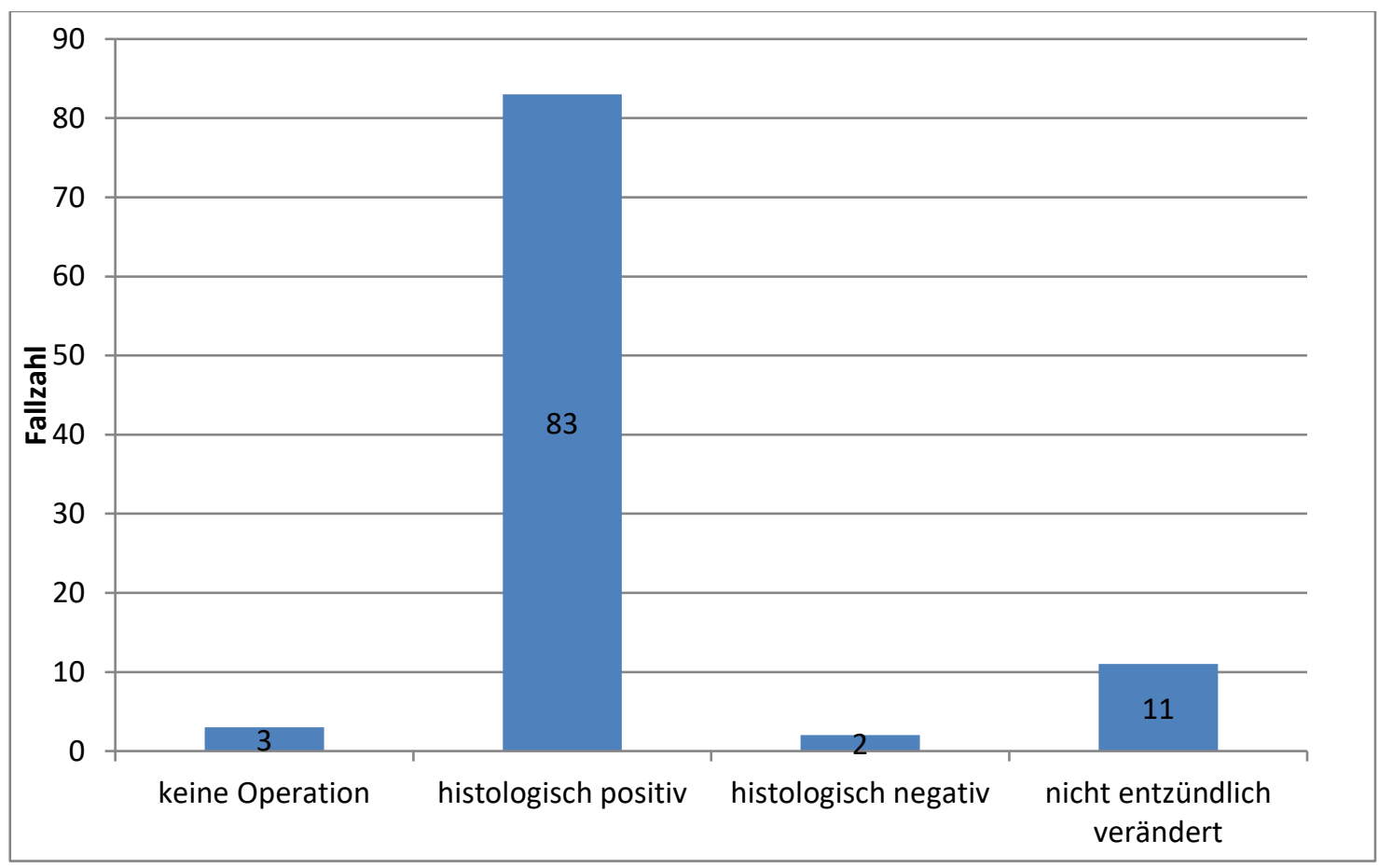

Abbildung 7: Histologische Ergebnisse bei klassischen Zeichen einer Appendizitis 


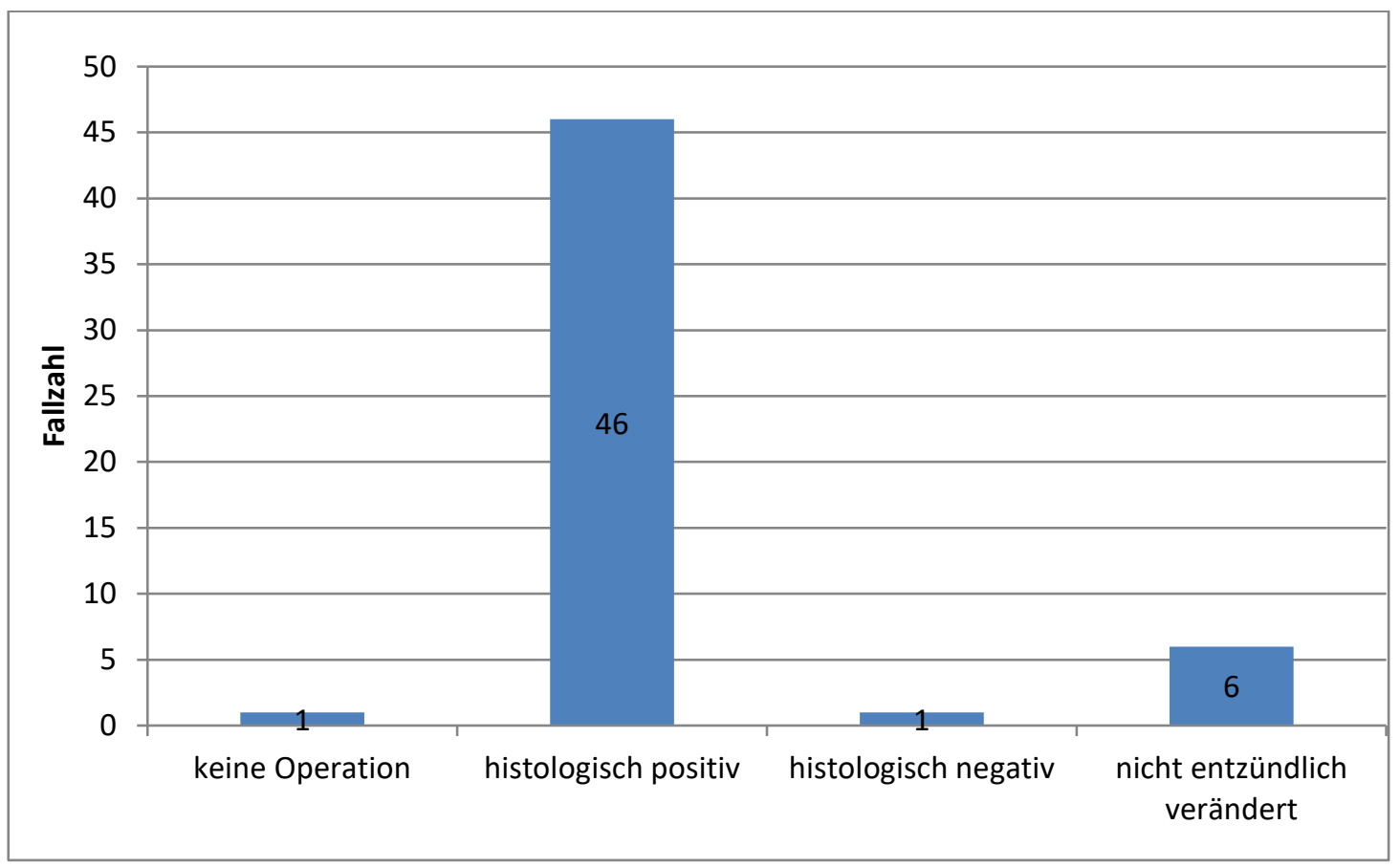

Abbildung 8: Histologische Ergebnisse bei nicht klassischen Zeichen einer Appendizitis

In beiden Grafiken wird deutlich, dass die überwiegende Mehrzahl histologisch positive Appendektomien war. Die übrigen Entitäten, also die bei denen vielleicht eine konservative Therapie hätte angewandt werden können, zusammengenommen machen hierbei prozentual beim Vorliegen von klassischen Zeichen einer Appendizitis 16,16\%, bei der Abwesenheit von klassischen Zeichen einer Appendizitis 15,09\% und insgesamt 15,78\% aus.

\subsubsection{Fieber}

Von den 152 Patienten dieses Kollektivs litten bei Aufnahme in der Klinik 11 (16,72\%) an Fieber. Sieben von diesen Patienten waren weiblich, vier männlich. Es zeigte sich bei allen eine CRP-Wert - Erhöhung (Normwert $<0,5 \mathrm{mg} / \mathrm{dl}$ ) in der Breite 0,7 bis 26,53mg/dl. Der Mittelwert lag hierbei bei 9,66 mg/dl, der Median bei 7,09mg/dl. Alle 11 Patienten wiesen klassische Zeichen einer Appendizitis auf. Zehn Patienten wurden operativ versorgt; hierbei zwei primär offen, einer sekundär offen und sieben laparoskopisch. Ein Patient wurde erfolgreich konservativ behandelt. Bis auf den konservativ behandelten Patienten wiesen alle histologischen Präparate eindeutig entzündliche Veränderungen auf. Ein Patient 
wies einen perityphlitischen Abszess, einer eine Vier-Quadranten-Peritonitis, einer eine gedeckte Perforation und fünf eine Peritonitis auf.

\subsection{Therapie}

\subsubsection{Offene Appendektomien}

Zehn Patienten (vier weiblich, sechs männlich) wurden primär mit einer offenen Operation therapiert, weitere elf Patienten (vier weiblich, sieben männlich) wurden primär laparoskopisch behandelt und es wurde dann auf ein offenes Vorgehen gewechselt.

Bei allen primär offen appendektomierten Patienten zeigte sich ein eindeutig entzündlich verändertes histologisches Präparat (also positive Histologie).

Bei den 11 Patienten, welche umgestiegen offen operiert wurden, zeigte sich ebenso bei allen ein eindeutig entzündlich verändertes Präparat, also eine positive Histologie sowie bei zehn Patienten Zeichen einer Peritonitis.

Bei einem Patienten (Nummer 78) erfolgte die Einweisung durch den Hausarzt mit einem unklaren Abdomen.

Nach der umgestiegen offenen Appendektomie, welche als histologisches Ergebnis eine chronisch rezidivierende Appendizitis mit distaler Lumenobliteration erbrachte, folgte ein schwerer komplizierter Verlauf mit Platzbauch-Entwicklung, mehrfachen intraabdominellen Lavagen, Zökumresektion und schließlich Entwicklung einer Infarktpneumonie, an welcher der Patient im stationären Verlauf verstarb.

Tabelle 4: Histologie der offenen Appendektomien

\begin{tabular}{|l|l|l|l|}
\hline Anzahl & positiv & negativ & nicht entzündlich \\
\hline 10 primär offen & 10 & 0 & 0 \\
\hline $\begin{array}{l}11 \text { umgestiegen } \\
\text { offen }\end{array}$ & 11 & 0 & 0 \\
\hline
\end{tabular}




\subsubsection{Laparoskopische Appendektomien}

129 Patienten (95 weiblich, 34 männlich) wurden laparoskopisch appendektomiert. 109 histologische Präparate dieser Patienten waren eindeutig entzündlich verändert, also positiv. 17 Präparate waren nicht entzündlich verändert und 3 Präparate waren histologisch negativ, zeigten also keine pathologischen Veränderungen.

Tabelle 5: Histologie der laparoskopischen Appendektomien

\begin{tabular}{|l|l|l|l|}
\hline Anzahl & positiv & negativ & nicht entzündlich \\
\hline 129 & 109 & 3 & 17 \\
\hline
\end{tabular}

\subsubsection{Konservatives Vorgehen}

Vier Patientinnen wurden konservativ behandelt. Bei zweien waren Nahrungskarenz und eine bedarfsweise Analgesie sowie eine intravenöse Volumengabe zur Erlangung der Beschwerdefreiheit ausreichend.

Bei einer Patientin wurde im Intervall (4 Monate nach der konservativ behandelten Appendizitis) eine laparoskopische Cholezystektomie durchgeführt. In dem Operationsbericht findet sich kein Hinweis auf eine Erkrankung der Appendix.

Eine weitere Patientin wurde durch einen niedergelassenen Chirurgen mit dem Verdacht auf Appendizitis eingewiesen. Nach Nahrungskarenz und Infusionstherapie war die Patientin beschwerdefrei. Sonografisch hatte sich intraabdominal wenig freie Flüssigkeit gezeigt. Differentialdiagnostisch käme hier auch eine rupturierte Ovarialzyste in Frage. Da die Patientin jedoch beschwerdefrei war, konnte diese Frage retrospektiv nicht geklärt werden.

\subsubsection{Anwendung von Scores}

Anhand der vorliegenden Daten konnten die in der Einleitung beschriebenen Score Systeme nicht angewendet werden. Das lag zum einen an der sehr unterschiedlichen Dokumentation der klinischen Untersuchungen, zum anderen an den in den Score- 
Systemen abgefragten teils recht speziellen Untersuchungen, die bei diesem Patientenkollektiv nicht erfasst wurden. So wurde beispielsweise die Anzahl der polymorphkernigen Leukozyten bei keinem Patienten bestimmt.

\subsection{Chirurgische Diagnose}

\subsubsection{Initiale chirurgische Beurteilung}

Von den 152 Patienten unseres Kollektivs wurde bei 120 Patienten klinisch bereits die Verdachtsdiagnose Appendizitis gestellt, welche sich später histologisch bestätigen ließ. Bei diesen 120 (78,94\%) Patienten war die initiale Diagnose also korrekt.

Bei 33 (21,71\%) Patienten war die initiale Beurteilung jedoch nicht korrekt.

So konnte bei zwei Patienten (Nummer 2 und 3) histologisch kein entzündliches Korrelat (dilatiertes Lumen, entzündungsfreie Appendix) gefunden werden (negative Appendektomie).

Bei 8 Patienten (Nummer 4, 5, 6, 84, 85, 101, 107, 125) zeigten sich histologisch nichtentzündliche Veränderungen der Appendix-Präparate (submucöse Lipomatose).

Drei Patientinnen (Nummer 50, 65 und 113) wurden initial mit vermuteten gynäkologischen Erkrankungen behandelt.

Bei Patientin Nummer 50 erfolgte die stationäre Einweisung durch einen niedergelassenen Gynäkologen mit dem Verdacht auf eine Ovarialzyste bei akuten Unterbauchschmerzen. In der durch die gynäkologische Abteilung der Agaplesion-Diakoniekliniken durchgeführten diagnostischen Laparoskopie zeigte sich dann eine Appendizitis. Die Appendektomie wurde dann auch von der Gynäkologie vorgenommen. Histologisch zeigte sich eine chronisch rezidivierende Appendizitis mit Lumenobliteration und Lokalperitonitis.

Patientin Nummer 65 stellte sich mit einer erneuten Episode immer wiederkehrender Bauchschmerzen vor. Sonografisch wurde eine Cholezystitis und eine unklare Raumforderung des rechten Ovars gesehen. Es wurde eine simultane laparoskopische Cholezystektomie und Ovarektomie rechts geplant. Intraoperativ zeigte sich zusätzlich der Verdacht auf eine Endometriose unter Einbeziehung der Appendix, sodass zusätzlich auch 
eine Appendektomie durchgeführt wurde. Histologisch zeigte sich eine im Spitzenbereich perforierte ulcerophlegmonöse Appendizitis.

Bei Patientin Nummer 113 erfolgte die stationäre Aufnahme bei unklaren abdominellen Schmerzen. Eine initial durchgeführte Ösophagogastroduodenoskopie war unauffällig. Im Verlauf zeigte sich sonografisch intraabdominal etwas freie Flüssigkeit, sodass dann die Indikation für eine diagnostische Laparoskopie gestellt wurde, wobei sich zystische Ovarien zeigten. Es wurde jedoch eine „Gelegenheits- - Appendektomie“ durchgeführt. Histologisch zeigte sich dann eine distale Lumenobliteration der Appendix mit submucosaler Proliferation passend zu einer abgelaufenen Appendizitis (Zitat aus dem Histologiebericht).

Bei 15 Patienten (Nummer 11, 31, 35, 37, 39, 42, 45, 66, 106, 107, 125, 128, 129, 130, 135) wurde initial eine andere Ursache als Auslöser der Beschwerden vermutet und erst im Verlauf die Diagnose einer Appendizitis gestellt. Alle diese 15 Patienten wurden laparoskopisch appendektomiert. 13 waren histologisch positiv, also eindeutig entzündlich verändert. Nur zwei histologische Präparate waren nicht entzündlich verändert.

Bei fünf Patienten (79, 81, 82, 83, 97) wurde initial von einer komplizierten Appendizitis ausgegangen, welche sich später als unkompliziert herausstellte.

Alle diese 5 Patienten wurden laparoskopisch operiert.

Eine Patientin (Nummer 97) litt seit 6 Tagen an Unterbauchbeschwerden und hatte sich in einer anderen gynäkologischen Klinik behandeln lassen. Dort war sie entlassen worden und stellte sich dann auf der Notaufnahme der Agaplesion-Diakoniekliniken vor.

Histologisch waren bei allen 5 Patienten eindeutig entzündliche Präparate zu identifizieren.

\subsubsection{Wechsel der Diagnose von unkomplizierter zu komplizierter Appendizitis}

Von den 152 untersuchten und behandelten Patienten dieses Kollektivs wurde im Verlauf der Behandlung bei 18 Patienten die Diagnose von unkomplizierter zu komplizierter Appendizitis oder entgegengesetzt gewechselt.

Ein Wechsel geschah bei den Patienten mit der Nummer 11, 15, 20, 27, 28, 31, 35, 39, 47, 49, 60, 62, 65, 79, 115, 136, 143, 151 und 152. 
Bei Patient Nummer 11 bestanden seit zwei Tagen rechtsbetonte Unterbauchschmerzen, klassische Zeichen einer Appendizitis lagen nicht vor, sonografisch zeigte sich ein unauffälliger Befund, erst eine Computertomografie des Abdomens zeigte ein entzündliches Konglomerat am Zökum, woraufhin eine Laparoskopie durchgeführt wurde. Die Histologie lautete „perforierte Appendizitis“. Also erfolgte ein Wechsel von unkomplizierter zu komplizierter Appendizitis.

Bei Patientin Nummer 15 lagen ebenfalls keine klassischen Zeichen einer Appendizitis vor. Nachdem es unter konservativer Therapie zu keiner Besserung kam, wurde eine diagnostische Laparoskopie durchgeführt und hierbei dann eine Appendektomie mit dem histologischen Ergebnis einer ulcerophlegmonösen Appendizitis mit Durchwanderungsperitonitis. Also erfolgte ein Wechsel von unkomplizierter zu komplizierter Appendizitis.

Ähnlich verhielt es sich bei Patientin Nummer 20. Diese wurde zur Beobachtung stationär aufgenommen, am Folgetag zeigten sich klassische Zeichen einer Appendizitis, woraufhin eine laparoskopische Appendektomie durchgeführt wurde mit dem Ergebnis einer ulcerophlegmonösen Appendizitis mit Durchwanderungsperitonitis. Also erfolgte ein Wechsel von unkomplizierter zu komplizierter Appendizitis.

Patientin Nummer 27 wurde von einer Hausärztin mit unklaren Unterbauchschmerzen eingewiesen, es wurde zunächst eine diagnostische Laparoskopie durchgeführt. Intraoperativ zeigte sich dann eine Appendizitis mit Lokalperitonitis, welche sich histologisch bestätigte. Also erfolgte ein Wechsel von unkomplizierter zu komplizierter Appendizitis.

Patientin Nummer 28 stellte sich mit seit wenigen Stunden bestehenden epigastrischen Schmerzen und Erbrechen in der Notaufnahme der Agaplesion - Diakoniekliniken vor. Nach zwölfstündiger Beobachtung lokalisierte sich das Schmerzmaximum im rechten Unterbauch, was zu einer laparoskopischen Appendektomie führte. Das histologische Ergebnis zeigte eine ulcerophlegmonöse Appendizitis mit Durchwanderungsperitonitis. Also erfolgte ein Wechsel von unkomplizierter zu komplizierter Appendizitis.

Bei Patient Nummer 31 war bei diffusen Bauchschmerzen zunächst eine Ösophagogastroduodenoskopie und eine Röntgenkontrastaufnahme durchgeführt worden. Hierbei zeigte sich eine Stenose im Sinne eines Dünndarmileus, woraufhin zunächst eine Laparoskopie begonnen wurde, was dann auf eine offene Appendektomie gewechselt wurde. Histologisch zeigte sich eine ulcerophlegmonöse und hämorrhagische Appendizitis 
mit Durchwanderungsperitonitis. Also erfolgte ein Wechsel von unkomplizierter zu komplizierter Appendizitis.

Patientin Nummer 35 klagte seit dem Vortag über Unterbauchschmerzen, wurde zur Beobachtung aufgenommen und zeigte am Folgetag klassische Zeichen einer Appendizitis und wurde am Folgetag laparoskopisch appendektomiert. Histologisch zeigte sich eine ulcerophlegmonöse Appendizitis mit fibrinöser Peritonitis. Also erfolgte ein Wechsel von unkomplizierter zu komplizierter Appendizitis.

Bei Patientin Nummer 39 wurde initial eine komplizierte Appendizitis vermutet. Sie wurde mit seit 24 Stunden bestehenden Unterbauchschmerzen und Fieber aufgenommen. Es erfolgte eine laparoskopische Appendektomie. Histologisch zeigte sich eine chronisch rezidivierende und akut exacerbierte Appendizitis ohne Anhalt für Peritonitis oder Periappendizitis. Es erfolgte hier also der Wechsel von einer komplizierten zu einer unkomplizierten Appendizitis.

Patientin Nummer 47 stellte sich zuerst bei einer niedergelassenen Gynäkologin mit Fieber und diffusen Unterbauchbeschwerden vor. Nachdem die ambulante gynäkologische Untersuchung unauffällig war, erfolgte die Einweisung mit der Verdachtsdiagnose Appendizitis. Klassische Zeichen einer Appendizitis fehlten. Nach 48 stündiger Beobachtung zeigte sich sonografisch eine Kokarde, woraufhin eine laparoskopische Appendektomie erfolgte. Histologisch zeigte sich eine chronisch - rezidivierende akut exacerbierte Appendizitis mit Durchwanderungsperitonitis. Also erfolgte ein Wechsel von unkomplizierter zu komplizierter Appendizitis.

Bei Patientin Nummer 49 waren akute rechtsseitige Unterbauchschmerzen aufgetreten, die nach 24 stündiger Beobachtung und konservativer Therapie im Krankenhaus rückläufig waren. Aufgrund eines eindeutigen Sonografiebefundes (Appendixkokarde) wurde jedoch eine laparoskopische Appendektomie mit dem histologischen Ergebnis einer ulcerophlegmonösen Appendizitis mit fibrinöser Peritonitis durchgeführt. Also erfolgte ein Wechsel von unkomplizierter zu komplizierter Appendizitis.

Patient Nummer 60 stellte sich mit seit drei Tagen bestehenden rechtsseitigen Unterbauchschmerzen bei einem niedergelassenen Chirurgen vor, der eine Einweisung mit dem Verdacht auf Appendizitis veranlasste. Bei schwierigen Sonografiebedingungen wurde eine Computertomografie des Abdomens durchgeführt. Daraufhin erfolgte zunächst eine laparoskopische, im Verlauf dann offene Appendektomie. Histologisch zeigte sich eine 
perforierte ulcerophlegmonöse Appendizitis. Also erfolgte ein Wechsel von unkomplizierter zu komplizierter Appendizitis.

Patient Nummer 62 hatte seit fünf Tagen zunehmende Unterbauchschmerzen und war von seinem Hausarzt initial behandelt worden. Bei Schmerzprogredienz erfolgte die Klinikeinweisung mit der Verdachtsdiagnose Appendizitis.

Bei Aufnahme bestanden klassische Zeichen einer Appendizitis, woraufhin eine laparoskopische Appendektomie erfolgte. Histologisch zeigte sich ein perityphlitischer Abszess, die Appendix jedoch war histologisch entzündungsfrei (Wechsel von unkompliziert zu kompliziert?).

Patientin Nummer 79 hatte seit zwei Tagen Bauchschmerzen, zuerst im Mittelbauch, dann im rechten Unterbauch. Bei klassischen Appendizitiszeichen wurde eine laparoskopische Laparoskopie bei Verdacht auf komplizierte Appendizitis durchgeführt. Histologisch zeigte sich dann eine initiale ulzeröse Appendizitis. Es erfolgte also der Wechsel der Diagnose von komplizierter zu unkomplizierter Appendizitis.

Patientin Nummer 115 stellte sich im 59sten Lebensjahr mit seit dem Vorabend bestehenden rechtsseitigen Unterbauchschmerzen vor. Sie berichtete, eine solche Episode bereits mit 22 Jahren erlebt zu haben. Damals sei es konservativ behandelt worden und sie habe bis zu der erneuten Aufnahme in der Agaplesion - Diakonieklinik keine Beschwerden mehr gehabt. Klinisch zeigte sich ein Druckschmerz mit Abwehrspannung im rechten Unterbauch. Es wurde ein konservativer Therapieversuch unternommen. Am Folgetag zeigte sich keine Besserung. Sonografisch wurde eine zystische Struktur am rechten Ovar und ein vorbekanntes Uterusmyom gesehen und eine diagnostische Laparoskopie durchgeführt. Hierbei zeigte sich eine retrozökal gelegene phlegmonös aufgetriebene Appendizitis. Histologisch wurde der Befund als ulcerophlegmonöse Appendizitis mit florider Periappendizitis beschrieben. Also erfolgte ein Wechsel der Diagnose von unkomplizierter zu komplizierter Appendizitis.

Der Patient Nummer 136 litt seit zwei Tagen an linksbetonten Unterbauchschmerzen. Klassische Zeichen einer Appendizitis bestanden nicht, eine Sonografie erbrachte keinen auffälligen Befund, sodass eine Computertomografie des Abdomens durchgeführt wurde, bei welcher sich ein entzündliches Konglomerat am Zökum zeigte. Intraoperativ zeigte sich ein perityphlitischer Abszess und histologisch eine ulcerophlegmonöse Appendizitis mit Periappendizitis und fibrinöser Peritonitis. Also erfolgte ein Wechsel von unkomplizierter zu komplizierter Appendizitis. 
Patient Nummer 143 litt seit weniger als 24 Stunden unter rechtsseitigen Unterbauchbeschwerden und wurde zunächst zur Beobachtung stationär aufgenommen. Initial zeigten sich ein Druckschmerz im rechten Unterbauch und ein unauffälliger Sonografiebefund. Nach einem halbtägigen Beobachtungsintervall war eine Schmerzprogredienz, eine Abwehrspannung und sonografisch eine Kokarde über dem Appendix gesehen worden, sodass eine laparoskopische Appendektomie durchgeführt wurde. Histologisch zeigte sich dann eine ulcerophlegmonöse Appendizitis mit Periappendizitis und Serositis, also eine komplizierte Appendizitis. Also erfolgte ein Wechsel von unkomplizierter zu komplizierter Appendizitis.

Patientin Nummer 151 litt seit über einer Woche an Kopf- und Gliederschmerzen. Bauchschmerzen wurden erst seit einigen Tagen beklagt. Bei einer ambulanten gynäkologischen Untersuchung war dann intraabdominal freie Flüssigkeit aufgefallen, sodass eine Krankenhauseinweisung erfolgte. Bei der Aufnahme zeigten sich keine klassischen Appendizitiszeichen. Die initial bestimmten Entzündungswerte (Leukozytenzahl und CRP) waren im Beobachtungsintervall sogar rückläufig. Sonografisch zeigte sich im Verlauf aber eine Appendixkokarde, sodass eine laparoskopische Appendektomie erfolgte. Histologisch zeigte sich eine akute katarrhalische Appendizitis. Also erfolgte ein Wechsel von komplizierter zu unkomplizierter Appendizitis.

Patientin Nummer 152 litt seit ca. 24 Stunden unter diffusen Bauchschmerzen und Erbrechen. Initial zeigte sich klinisch ein mäßiger Druckschmerz über dem Mc-BurneyPunkt. Die Sonografie fiel unauffällig aus. Nach halbtägigem Beobachtungsintervall wurde sich bei ausbleibender Besserung zu einer diagnostischen Laparoskopie entschieden. Hierbei erfolgte eine Appendektomie. Das histologische Ergebnis lautete akute ulcerophlegmonöse Appendizitis mit Serositis. Also erfolgte ein Wechsel von unkomplizierter zu komplizierter Appendizitis.

Insgesamt wurde also lediglich dreimal (Patienten 39, 79, 151) von kompliziert zu unkompliziert gewechselt.

Der Wechsel von der Diagnose unkomplizierter zu komplizierter Appendizitis erfolgte 16mal. 


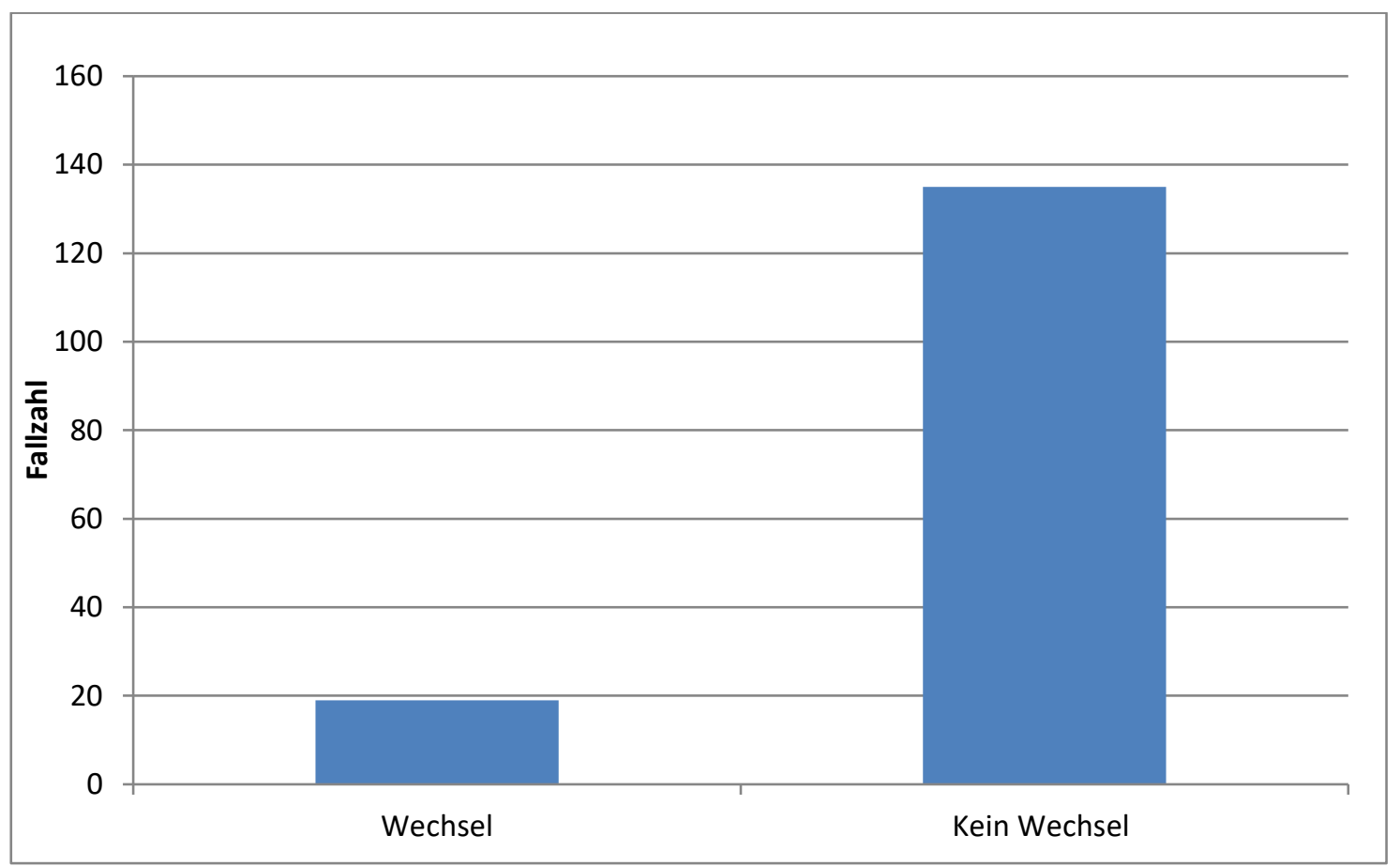

Abbildung 9: Diagnosewechsel 


\section{DISKUSSION}

In den letzten Jahren häufen sich die Hinweise, dass eine konservative Therapie einer unkomplizierten Appendizitis durchführbar und mit einem geringeren Risiko für die Patienten behaftet ist, als das bisherige Vorgehen, nämlich, dass jede Appendizitis schnellstmöglich zu operieren sei (Kelly et al. 2015).

Die retrospektive Analyse der Patientendaten, die im Zeitraum von 2012 bis 2015 in der chirurgischen Abteilung der Agaplesion-Diakoniekliniken Kassel mit der Diagnose Appendizitis behandelt wurden, hatte zum Ziel, Erkenntnisse darüber zu gewinnen, ob und unter welchen Umständen eine konservative Therapie einer unkomplizierten Appendizitis möglich, durchführbar sowie für den Patienten sicher und vertretbar ist.

Des Weiteren sollten Erkenntnisse darüber gewonnen werden, wie hoch die Diagnosesicherheit ist, also mit welcher Wahrscheinlichkeit die Diagnose einer Appendizitis zutreffend ist.

Dies ist deshalb so entscheidend, da, wie oben bereits erwähnt, die ärztliche Diagnosestellung durch kein bisher bekanntes Verfahren (seien es Score-Systeme oder der bedenkenlose Einsatz von bildgebenden Verfahren) ersetzt werden kann.

Diese Ergebnisse werden mit aktueller Literatur zu diesem Thema verglichen, um Evidenz für eine konservative Therapie von unkomplizierten Appendizitiden zu erlangen.

Unangefochten bleibt hierbei, dass eine komplizierte Appendizitis selbstverständlich operativ versorgt werden muss. Die These, dass eine unkomplizierte Appendizitis konservativ behandelt werden kann, existiert bereits seit Jahrzehnten.

Bereits 1959 veröffentlichte Coldrey diese These. (Coldrey 1956). Allerdings gibt es bis heute keine allgemeine Therapieempfehlung zur Behandlung einer unkomplizierten Appendizitis. Das allgemeine Vorgehen, dass allein bei dem Verdacht auf eine Appendizitis eine stationäre Therapie zu erfolgen hat, kann allein anhand der hier erhobenen Daten in Zweifel gezogen werden. Aber auch die hier hinzugezogene Literatur legt die Vermutung nahe, dass eine konservative Therapie einer unkomplizierten Appendizitis möglich und bei ausbleibender Besserung, also letztlich der Entwicklung einer komplizierten Appendizitis trotz initialer konservativer Therapie einer unkomplizierten Appendizitis, nicht mit einer erhöhten Gefährdung des Patienten einhergeht. 


\subsection{Demografische Daten}

Verglichen mit der finnischen Studie von Salminen et al. (2015) ist das hier untersuchte Kollektiv im Durchschnitt jünger. Der Median in dem Patientenkollektiv von Salminen et al. (2015) liegt für die Appendektomiegruppe bei 35 Jahren, bei der Antibiotikagruppe bei 33 Jahren und bei unserem Kollektiv bei 29 Jahren (Salminen et al. 2015).

Zusätzlich sollte man erwähnen, dass bei Salminen Patienten über 60 Jahren von der Studie ausgeschlossen wurden. In der hier untersuchten Patientengruppe lag der Anteil der über 60Jährigen bei $11,8 \%$.

Allerdings wurden alle über 60-Jährigen in unserer Patientengruppe operativ therapiert, sodass anhand dieser Daten unsere These, dass gerade bei über 60-Jährigen eine konservative Therapie anzustreben wäre (Kotaluoto et al. 2016), nicht unterstützt werden kann, aber auch nicht widerlegt wird.

In der Arbeit von Kotaluoto et al. (2016) wird beschrieben, dass bei über 60-Jährigen Patienten eine erhöhte Komplikationsrate und eine erhöhte Mortalität bei Appendektomien beobachtet werden konnte.

In unserem Kollektiv waren von den 18 Patienten, die über 60 Jahre alt waren, 14 an einer komplizierten Appendizitis erkrankt, vier an einer unkomplizierten Appendizitis. Alle Patienten wurden operiert.

Bei acht Patienten $(44,4 \%)$ zeigte sich ein komplizierter Verlauf. Drei Patienten wurden primär offen operiert, der eine aufgrund einer Vier-Quadranten-Peritonitis und eines komplizierten postoperativen Verlaufes mit acht Tagen Intensivpflichtigkeit, der andere aufgrund eines perityphlitischen Abszesses, der eine Dünndarmteilresektion nötig machte, und der dritte aufgrund einer nötigen Zökumresektion und Entwicklung eines Platzbauches. Zwei Patienten mussten erneut laparoskopiert werden, der eine aufgrund eines postoperativen Hämatoms, der andere für mehrfache Lavagen bei einer ESBL-Besiedelung (Extended Spectrum Beta Lactamase).

Drei Patienten wurden sekundär offen operiert.

Auch bei der nur sehr kleinen Patientenzahl von 18 Patienten fällt diese hohe Komplikationsrate auf. Da allerdings alle der 18 histologischen Ergebnisse positiv waren, war auch retrospektiv die Operationsindikation immer richtig. 
Dennoch sollte anhand dieser Daten zu besonderer Sorgfältigkeit bei der Diagnosestellung und Therapie einer Appendizitis bei Patienten mit einem Lebensalter über 60 angehalten werden. Weitere Studien sind nötig, um die Frage zu klären, ob eine konservative Therapie einer unkomplizierten Appendizitis bei diesen Patienten besondere Vorteile bietet.

\subsection{Konservative Therapie}

Es gibt mehrere Studien und seit Jahrzehnten Hinweise, welche nahelegen, dass eine konservative Therapie einer unkomplizierten Appendizitis durchführbar, effektiv und sicher für den Patienten sein kann (Kim et al. 2015, Coldrey 1956, Hansson et al. 2009, Styrud et al. 2006, Vons et al. 2011, Kelly et al. 2015, Schumpelick et al. 2004).

Dennoch gibt es keine einheitlichen Empfehlungen hierzu. Die bisherigen Empfehlungen lauten, dass eine Appendizitis, ohne Unterscheidung ob unkompliziert oder kompliziert, unverzüglich zu operieren ist (Kim et al. 2015, Schumpelick et al. 2004).

Würde eine operative Therapie unterlassen, drohen Perforation, Abszedierung und in letzter Konsequenz der Tod des Patienten.

Auch allein der Verdacht auf das Vorliegen einer Appendizitis gilt als relative Operationsindikation (Löhnert 2000).

Es ist jedoch nicht genau definiert, was unverzüglich bedeutet. Unstrittig ist die Operationsindikation für eine komplizierte Appendizitis im Sinne eines akuten Abdomens. Wie sollte jedoch bei einem Patienten verfahren werden, der sich ohne Komorbiditäten mit einem rechtsseitigen Unterbauchschmerz, klassischen Zeichen einer Appendizitis und ohne Erbrechen erstmals vorstellt? Nach den Daten von Rollins et al. (2016) sollte mit einer antibiotischen Therapie begonnen werden. Dies könnte auch ambulant z. B. durch niedergelassene Hausärzte, Chirurgen oder Gynäkologen erfolgen. Auch wäre ambulant eine engmaschige Kontrolle gewährleistet. Aus ökonomischen Gesichtspunkten hätte dieses Vorgehen den Vorteil, dass teurere stationäre Therapien umgangen werden könnten.

Im Mittel lag die Aufenthaltsdauer unserer Patienten bei 5,65 Tagen (Median 5 Tage, Minimum ein Tag, Maximum 29 Tage).

In den Anleitungen und Empfehlungen zur Behandlung einer Appendizitis steht, „das Schicksal einer Appendizitis entscheidet sich in den ersten 24 bis 48 Stunden“ (Schumpelick et al. 2004). 
In dem hier untersuchten Patientenkollektiv hatte die überwiegende Mehrzahl (69 von 152, also 45,39\%) der Patienten jedoch länger als 48 Stunden Beschwerden, bevor die erste ärztliche Untersuchung stattfand. Nimmt man die Gruppe der Patienten hinzu, die über chronisch-rezidivierende Beschwerden klagten, kommt man sogar auf 81 von 152 Patienten $(53,2 \%)$. Einige Patienten klagten seit zwei Wochen über Beschwerden, andere intermittierend seit Monaten (die längste Beschwerdedauer waren über 18 Monate). Hinweise auf eine erhöhte Komplikationsrate oder Mortalität bei einem operativen Vorgehen fanden sich in dieser Gruppe jedoch nicht.

Auch wenn nur lediglich vier der hier untersuchten Patienten tatsächlich konservativ behandelt wurden, so gibt es dennoch weitere Hinweise für die erfolgreiche Durchführung einer konservativen Therapie einer unkomplizierten Appendizitis.

Eine Patientin war nach konservativer Therapie im 22. Lebensjahr 37 Jahre lang beschwerdefrei bis sie sich im 59. Lebensjahr mit einer komplizierten Appendizitis operieren ließ.

In der Arbeit von Salminen et al. (2015) konnten von der Gruppe der mit Antibiotika behandelten Patienten 72,7\% (186 Patienten von insgesamt 457 Patienten) erfolgreich behandelt werden und benötigten in der Nachbeobachtung (ein Jahr Nachbeobachtungszeit) keine Operation.

Rechnet man diese 186 Patienten auf die Gesamtzahl der von Salminen et al. (2015) untersuchten Patienten (457) hoch, so erhält man immer noch einen Wert von 40,7\%. In unserem Patientenkollektiv wurden lediglich vier Patienten konservativ behandelt, was 2,63\% ergibt. Nimmt man die histologisch negativen und nicht entzündlich veränderten histologischen Ergebnisse mit hinzu erhält man trotzdem nur 15,78\%.

In der Zusammenschau aller hier erhobenen Befunde und einbezogenen Literatur gibt es also klare Hinweise für eine erfolgreiche und sichere sowie auch längerfristig zur Heilung führenden konservativen Therapie einer unkomplizierten Appendizitis.

Da es keine Hinweise auf eine erhöhte Mortalität oder Komplikationsrate bei im weiteren Verlauf operierten Patienten gibt, sollte bei einer unkomplizierten Appendizitis zuerst ein konservativer Therapieversuch unternommen werden.

Alle in unserer Patientengruppe konservativ therapierten Patienten konnten peroral Nahrung und Flüssigkeit aufnehmen. Ein Patient wurde bereits ambulant mit Amoxicillin und Clavulansäure behandelt und nach einem Tag stationärer Beobachtung beschwerdefrei entlassen. 
$\mathrm{Ob}$ es unter Umständen gerechtfertigt und sicher ist, bei dem Verdacht auf eine unkomplizierte Appendizitis sogar initial auf eine stationäre Behandlung zu verzichten und eine perorale Antibiose auch ambulant (durch Hausärzte, niedergelassene Chirurgen und Gynäkologen) applizieren zu lassen, kann anhand der hier vorliegenden Daten nur vermutet werden, erscheint aber durchaus denkbar. Diese These könnte mit weiteren prospektiven Untersuchungen geklärt werden.

Meine eigenen Erfahrungen aus dem Alltag in einer allgemeinmedizinischen Praxis sind, dass eine Behandlung mit Amoxicillin und Clavulansäure unter engmaschiger (täglicher) Kontrolle und der genauen Aufklärung des Patienten durchführbar ist und zu einer Heilung bei einer unkomplizierten Appendizitis führen kann. Der Patient muss nur ausführlich über die Behandlung aufgeklärt und informiert werden, sodass es ihm möglich ist, auf Warnsignale $\mathrm{zu}$ achten und bei Verschlechterung die entsprechenden Schritte, wie Alarmierung des Rettungsdienstes oder Vorstellung in einer Klinik einzuleiten.

Es gibt derzeit keine allgemein gültigen Leitlinien zur Therapie einer Appendizitis. Jedoch wurde bereits im Jahre 1886 von Fitz vermutet, dass konservative Therapien einer Appendizitis möglich sind und dass einige Patienten eine Appendizitis auch ohne Behandlung überlebt hatten $(36,38)$. Fitz (1886) hatte bei Autopsien beobachtet, dass es Hinweise auf abgelaufene Appendizitiden gab, welche bei den Betroffenen jedoch nicht mit dem Tod in Zusammenhang stand, weshalb er diese Patienten autopsiert hatte (Fitz 1886). 1956 veröffentlichte Coldrey die These, dass eine konservative Therapie einer Appendizitis möglich sei. (Coldrey 1956)

Nehmen wir die deutschen Leitlinien einer pathophysiologisch ähnlichen Erkrankung wie die Appendizitis, nämlich die Leitlinie zur Divertikulitis - Therapie, so steht dort, dass bei unkomplizierter links- wie rechtsseitiger Divertikulitis ohne das Vorliegen von Risikofaktoren sogar unter engmaschiger ärztlicher Kontrolle auf eine Antibiotikagabe verzichtet werden kann, beim Vorliegen von Risikofaktoren für einen komplizierten Verlauf sollten Antibiotika zum Einsatz kommen. (Leifeld et al. 2014)

Die empfohlenen Antibiotika sind Cefuroxim, Ciprofloxacin, jeweils in Kombination mit Metronidazol, Ampicillin/Sulbactam, Moxifloxacin und Piperacillin/Tazobactam (Leifeld et al. 2014).

Diese Antibiotika sollen das zu erwartende polymikrobielle Erregerspektrum erfassen und lokalen Resistenzlagen angepasst werden (Leifeld et al. 2014). 
Das zu erwartende polymikrobielle Spektrum dürfte bei einer Appendizitis ähnlich sein. In unserer Patientengruppe wurde ein Patient ambulant mit Amoxicillin und Clavulansäure behandelt und nach kurzer stationärer Beobachtung beschwerdefrei entlassen.

Aufgrund der engen pathophysiologischen Beziehung zwischen einer Divertikulitis und einer Appendizitis wäre ein ähnliches Vorgehen in der Therapie naheliegend.

Also wäre es denkbar, eine unkomplizierte Appendizitis unter engmaschiger ärztlicher Kontrolle und ohne das Vorliegen von Risikofaktoren für einen komplizierten Verlauf (Alter, Komorbiditäten) sogar ohne Antibiotika zu behandeln?

Wenn es sich bei einer unkomplizierten Appendizitis um einen lokalen Prozess ohne systemische Reaktion handelt, wäre es dann auch möglich, eine unkomplizierte Appendizitis mit Mesalazin (offene Empfehlung in den Leitlinien zur Therapie einer Divertikulitis) oder nicht systemisch resorbierbaren Antibiotika wie Rifaximin erfolgreich zu behandeln? Hierzu liegen bisher keine Daten vor. Da es jedoch, wie oben bereits erwähnt keine Hinweise für erhöhte Komplikationsraten bei einem sekundär operativen Vorgehen gibt, sollten hierzu weitere Untersuchungen und Studien vorgenommen werden.

\subsection{Laborchemische Daten und die therapeutische Konsequenz}

Von den 152 Patienten unseres Kollektivs wurde bei 151 Patienten Blut abgenommen. Es konnte weder für die Leukozytenzahl noch den CRP-Wert nachgewiesen werden, dass es eine therapeutische Konsequenz nur aufgrund der erhobenen Laborwerte gegeben hat. Vielmehr war der klinische Status des Patienten ausschlaggebend.

In den Leitlinien zur Therapie einer Divertikulitis wird die Erhebung von Leukozytenzahl und CRP-Wert neben anderen Laboranalysen wie Urinstatus als Basisdiagnostik empfohlen (Leifeld et al. 2014).

Hier wird aber auch klar dargelegt, dass diese Laboruntersuchungen innerhalb von 48 Stunden wiederholt werden sollen, um eine Krankheitstendenz anzuzeigen.

So wird dort ein starker Anstieg des CRP-Wertes auf über $20 \mathrm{mg} / 1$ als Zeichen für eine Perforation gewertet. CRP-Werte kleiner $5 \mathrm{mg} / 1$ beinhalten einen negativ-prädiktiven Wert für eine Perforation (Leifeld et al. 2014, von-Mühlen et al. 2015).

Bei unseren Patienten wurden diese Werte $151 \mathrm{mal}$ bei Aufnahme in die Klinik bestimmt. $21 \mathrm{mal}$ wurden keine Verlaufskontrollen angefertigt und bei den übrigen 130 Patienten wurden diese Werte vor Entlassung nochmals kontrolliert. Wobei hier zu beobachten war, 
dass auch wenn die Werte der Verlaufskontrolle höher waren, als die initialen, wobei die Erhöhung auch durchaus durch den operativen Eingriff bedingt sein könnten, keine therapeutische Konsequenz hieraus abzuleiten war.

Die Patienten wurden also mit steigenden Werten durchaus auch entlassen. Auch hier war einzig der klinische Status entscheidend. Diese Daten decken sich mit einer Studie von Tind et al. (2015), die ebenso zu dem Ergebnis gelangte, dass CRP-Wert und Leukozytenzahl Bestimmung keinen signifikanten Einfluss auf das weitere therapeutische Vorgehen haben (Tind et al. 2015).

Geht man davon aus, dass ein erhöhter CRP-Wert eine systemische Reaktion auf eine Entzündung darstellt, so ließe sich daraus ableiten, dass bei einem erhöhten CRP-Wert eine antibiotische Therapie wie oben beschrieben gerechtfertigt wäre. Gerade im Bereich der ambulanten Patientenversorgung ist die zeitliche Diskrepanz zwischen einer ärztlichen Erstuntersuchung und dem Erhalt von Laborwerten jedoch oft zu lang (teils mehr als 24 Stunden). Insofern würde sich die Analyse von CRP-Wert und Leukozytenzahl nur sehr bedingt zur Therapiefindung eignen.

Die bereits mehrfach erwähnte Meta-Analyse von Rollins et al. (2016) postulierte, dass bereits bei dem Verdacht auf eine Appendizitis Antibiotika verordnet werden müssen. Denkbar wäre also, dass bei dem klinischen Verdacht auf eine Appendizitis umgehend mit einer antibiotischen Therapie begonnen wird, Leukozytenzahl und CRP-Wert sowie Urinstatus bestimmt werden und unter engmaschiger ärztlicher Kontrolle und symptomadaptierter Analgesie sowie abführenden Maßnahmen, eine operative Therapie umgangen werden könnte.

Die engmaschige Kontrolle müsste dann auch Verlaufskontrollen von CRP-Wert und Leukozytenzahl beinhalten, um bei gleichbleibend niedrigen Werten einen Therapieerfolg zu belegen, bzw. bei einem raschen Anstieg eine Verschlechterung nicht zu übersehen.

Bisher gibt es jedoch hierzu keine Daten, sodass dieses Vorgehen hier ausschließlich theoretischer Natur ist.

\section{4 Ärztliche Diagnose}

Die ärztliche Untersuchung ist in der Diagnostik einer Appendizitis das wichtigste Instrument und ist bisher durch kein anderes Verfahren, seien es Score-Systeme oder bildgebende Verfahren, zu ersetzen. 
In unserem Kollektiv wurde bei 78,04 \% (also 120 von 152 Patienten) gleich initial, also bei Aufnahme in die Klinik die richtige Diagnose gestellt. Bei 32 (21,05\%) Patienten gelang dies initial nicht. Hiervon wurden drei Patienten negativ appendektomiert, drei Patienten initial mit dem Verdacht auf eine gynäkologische Erkrankung laparoskopiert, wobei sich intraoperativ dann eine Appendizitis zeigte.

Bei 15 Patienten wurde erst im stationären Verlauf die Diagnose Appendizitis gestellt.

Bei fünf Patienten wurde initial eine komplizierte Appendizitis vermutet, welche sich dann als unkompliziert herausstellte.

Und acht Patienten wurden initial mit einer anderen Verdachtsdiagnose behandelt.

Insgesamt, also wenn man nicht nur die initial richtigen Diagnosen, sondern auch die im Verlauf letztlich richtigen Diagnosen zusammennimmt, erhält man, dass lediglich bei drei (1,97\%) Patienten negative Appendektomien durchgeführt wurden. Bei 17 Patienten zeigte das histologische Ergebnis nicht entzündliche Veränderungen. Nimmt man die histologisch negativen und die nicht entzündliche veränderten histologischen Ergebnisse zusammen, erhält man 20 Patienten (13,15\%).

Bei allen übrigen Patienten wurde im Verlauf noch die richtige Diagnose gestellt. Somit läge die Diagnosesicherheit hierbei bei $98,65 \%$ bzw. 86,85\%, wenn man die nicht-entzündlich veränderten Histologien mit dazu nimmt.

Dazu muss jedoch gesagt werden, dass es sich bei unserem Patientenkollektiv um eine vorselektierte Gruppe handelt, nämlich Patienten mit der Entlassungsdiagnose „Appendizitis“. Um eine genauere Beurteilung der initialen wie auch gesamten Diagnosesicherheit vornehmen zu können, müsste somit ein unselektiertes Patientengut untersucht werden.

Andere Autoren gehen von Diagnosesicherheiten zwischen 60 und $90 \%$ aus, somit negativen Appendektomieraten von 10-40\% (Schorr et al. 2000).

\subsection{Perorale Aufnahme von Medikation und Flüssigkeit}

Die perorale Flüssigkeits- und Medikationsaufnahme sind für eine ambulante konservative Therapie unerlässlich. Auch vor dem Hintergrund, dass Erbrechen Hinweis auf eine peritoneale Reizung also eine komplizierte Appendizitis sein könnte, erscheint dies plausibel. Es wäre also nach der Meta-Analyse von Rollins et al. (2016) bei dem Verdacht auf eine unkomplizierte Appendizitis indiziert, peroral mit einer Antibiose zu beginnen. 
Gehen wir davon aus, dass das polymikrobielle Spektrum bei einer Appendizitis dem Spektrum bei einer Divertikulitis ähnelt, wäre es möglich, eine Antibiotikakombination aus Cefuroxim und Metronidazol (Leifeld et al. 2014) zu applizieren und unter täglicher ärztlicher Kontrolle auf eine Hospitalisation initial zu verzichten.

Die erhaltene perorale Aufnahme von Medikation und Flüssigkeit würde sich hierbei als einfacher Indikator in der Entscheidungsfindung für oder gegen eine Krankenhauseinweisung für niedergelassene Ärzte eignen. 


\section{ZUSAMMENFASSUNG}

Die akute Appendizitis ist eines der häufigsten chirurgischen Krankheitsbilder und ist die häufigste Indikation zu einer Notfalloperation in Deutschland. Jährlich werden in Deutschland zwischen 127.000 und 135.000 Appendektomien durchgeführt. (Kronman 2016, Nolting et al. 2011)

Die initiale Diagnose bzw. der Verdacht auf eine Appendizitis werden auch von niedergelassenen Ärzten (Allgemeinmedizinern, Internisten, Gynäkologen) gestellt und meist daraufhin eine Einweisung in ein entsprechendes Krankenhaus veranlasst, da es bisher als Fehler gilt, eine Appendizitis, ohne Unterscheidung zwischen unkompliziert oder kompliziert nicht unverzüglich zu operieren.

Es ist unumstritten, dass eine akute komplizierte Appendizitis operiert werden muss.

Dennoch gibt es seit Jahrzehnten Hinweise, dass eine unkomplizierte Appendizitis konservativ behandelt werden kann.

Auch die hier erhobenen Daten stützen die These, dass eine konservative Therapie einer Appendizitis möglich ist. Des Weiteren konnte hier kein Nachteil für ein sekundär operatives Vorgehen gefunden werden. Die überwiegende Mehrzahl der hier untersuchten Patienten hatte länger als 48 Stunden Beschwerden, bevor die erste ärztliche Untersuchung stattfand. Eine erhöhte Komplikationsrate bei den Patienten mit dieser Beschwerdedauer konnte nicht gefunden werden.

Somit wäre eine initiale konservative Therapie einer unkomplizierten Appendizitis gerechtfertigt, da es bei Krankheitsprogress unter der initialen Therapie keinen Hinweis auf eine höhere Komplikationsrate bei der operativen Therapie gibt.

Allerdings konnte bei dem Kollektiv der über 60-Jährigen eine relativ hohe Komplikationsrate $(44,4 \%)$ gefunden werden, wobei alle der hier untersuchten über 60 Jährigen Patienten letztlich ein histologisch positives Ergebnis zeigten.

Bei der Wahl der konservativen Therapie gibt es derzeit keine allgemeingültigen Therapieempfehlungen, weshalb hier versucht wurde, die Empfehlungen einer pathophysiologisch ähnlichen Erkrankung, der Divertikulitis, als möglicherweise auch auf die unkomplizierte Appendizitis anwendbar zur Diskussion zu stellen. 
Auch aus sozioökonomischen Gründen würde eine konservative Therapie einer unkomplizierten Appendizitis Vorteile bieten. Immerhin lag der Median der stationären Aufenthaltsdauer bei fünf Tagen (1 bis 29 Tage).

Zusammenfassend erscheint eine initiale konservative Therapie einer unkomplizierten Appendizitis als durchführbar und sicher und bei Krankheitsprogress nicht mit einer erhöhten Komplikationsrate für die operative Therapie verbunden zu sein. Bei erhaltener peroraler Flüssigkeits- und Medikationsaufnahme erscheint sogar eine ambulante Therapie als vertretbar. 


\section{LITERATURVERZEICHNIS}

Abele-Horn M (2014): Leitlinien zur Hygiene in Klinik und Praxis, Arbeitskreis Krankenhaus- und Praxishygiene der AWMF Klasse: S1+IDA Perioperative Antibiotikaprophylaxe, AWMF-Register Nr. 029/022

Andersson M, Andersson RE (2008): The appendicitis inflammatory response score: a tool for the diagnosis of acute appendicitis that outperforms the alvarado score. World J Surg $\underline{32}$, $1843-49$

Berrington de González A (2009): Projected cancer risks from computed tomographic scans performed in the United States in 2007. Arch Gen Intern Med 169, 2071

Birnbaum BA, Wilson SR (2000). Appendicitis at the millennium. Radiol Artif Intell $\underline{215}$, $337-348$

Brenner DJ, Hall EJ (2007): Computed tomography-an increasing source of radiation exposure. NEJM $\underline{357}, 2277-84$

Çiftçi F (2015): Laparoscopic vs mini-incision open appendectomy. World J Gastronintest Surg $\underline{7}, 267-72$

Coldrey E (1956): Treatment of acute appendicitis. BMJ 2, 1458-61

Ehlers AP, Talan DA, Moran GJ, Flum DA, Davidson GH (2016): Evidence for an antibiotics-first strategy for uncomplicated appendicitis in adults: A systematic review and gap analysis. J Am Coll Surg $\underline{222}$, 309-14

Fitz R (1886) Perforating inflammation of the veriform appendix with special reference to its early diagnosis and treatment. Trans Assoc Am Physicians 1886, 107-144 
Hansson J, Körner U, Khorram-Manesh A, Solberg A, Lundholm K (2009) Randomized clinical trial of antibiotic therapy versus appendicectomy as primary treatment of acute appendicitis in unselected patients. BJS $\underline{96}, 473-81$

Kelly ME, Khan A, Ur Rehman J, Waldron RM, Khan W, Barry K, Khan IZ (2015) A national evaluation of the conservative management of uncomplicated acute appendicitis: How common is this and what are the issues? Dig Surg $\underline{32}, 325-30$

Kim TH, Cho BS, Jung JH, Lee MS, Jang JH, Kim CN (2015) Predictive factors to distinguish between patients with noncomplicated appendicitis and those with complicated appendicitis. Ann Coloproctol $\underline{31}, 192-97$

Knebel P, Weigand MA, Büchler MW, Seiler CM (2011) Evidenzbasierte Antibiotikaprophylaxe in der Allgemein- und Viszeralchirurgie. Chirurg 2, 227-234

Kotaluoto S, Ukkonen M, Pauniaho SL, Helminen M, Sand J, Rantanen T (2017) Mortality related to appendectomy; a population based analysis over two decades in Finland. World J Surg $41,64-69$

Kronman MP, Oron AP, Ross RK, Hersh AL, Newland JG, Goldin A, Rangel SJ, Weissman SJ, Zerr DM, Gerber JS.(2016) Extended- versus narrower-spectrum antibiotics for appendicitis. Pediatrics $\underline{138}, 1$

Leifeld L, Germer CT, Böhm S, Dumoulin FL, Häuser W, Kreis ME, Labenz J, Lembcke B, Post S, Reinshagen M et al. (2014) S2k Leitlinie Divertikelkrankheit / Divertikulitis, Gemeinsame Leitlinie der Deutschen Gesellschaft für Gastroenterologie, Verdauungs- und Stoffwechselkrankheiten (DGVS) und der Deutschen Gesellschaft für Allgemein- und Viszeralchirurgie (DGAV) in Zusammenarbeit mit der Deutschen Gesellschaft für Ernährung (DGE), Deutsche Röntgengesellschaft, Deutsche Gesellschaft für Neurogastroenterologie und Motilität (DGNM), Deutsche Gesellschaft für Ultraschall in der Medizin (DEGUM), Deutsche Morbus Crohn/ Colitis ulcerosa Vereinigung (DCCVe.V.). Z Gastroenterol 52, 663-710 
Liang TJ, Liu SI, Tsai CY, Kang CH, Huang WC, Chang HT, Chen IS (2016): Analysis of recurrence management in patients who underwent nonsurgical treatment for acute appendicitis. Medicine (Baltimore) $\underline{95}, 3159$

Löhnert M (2000) Leitlinien zur Diagnostik und Therapie der Appendicitis. Bielefeld. URL https://slidex.tips/download/leitlinien-zur-diagnostik-und-therapie-der-appendicitis-1properative-diagnostik abgerufen am 31.01.2020

Meltzer AC, Baumann BM, Chen EH, Shofer FS, Mills AM (2013): Poor sensitivity of a modified alvarado score in adults with suspected appendicitis. Ann Emerg Med $\underline{62}$, 126-31

Montali I, von Flüe M (2008): Die akute Appendizitis heute. Schweiz Med. Forum $\underline{8}$, 451455

Nekolla EA, Schegerer J, Griebe J, Brix G (2017): Häufigkeit und Dosis diagnostischer und interventioneller Röntgenanwendungen. Radiologe $\underline{57}$, 555-562

Nolting HD, Zich K, Deckenbach B, Gottberg A, Lohmann K, Klemperer D, Grote-

Westrick M, Schwenk U: Faktencheck Gesundheit. Regionale Unterschiede in der Gesundheitsversorgung. Bertelsmann Stiftung, Gütersloh 2011

O’Malley ME., Alharbi F, Chawla TP, Moshonov H (2016) CT following US for possible appendicitis: Anatomic Coverage. Eur Radiol Exp 26, 532-38

Orscheln ES., Trout AT (2016) Appendiceal Diameter: CT versus sonographic measurements. Pediatr Radiol 뜨, 316-21

Panknin HT (2015) Antibiotikatherapie statt Appendektomie? Krankenhauspharmazie $\underline{\text { 36, }}$ 13

Putzki H, Reichert B (1988) Does measuring axillo-rectal temperature difference help in the diagnosis of acute appendicitis? Langenbecks Archiv für Chirurgie $\underline{373}$, 310-12 
Riede UN (Hrsg.), Schaefer HE, von Herbay A, Krekeler GR: Allgemeine und spezielle Pathologie. 4. Auflage; Georg Thieme Verlag, Stuttgart 718-731, 2001

Rollins KE, Varadhan KK, Neal KR, Lobo DN.(2016) Antibiotics versus appendicectomy for the treatment of uncomplicated acute appendicitis: An updated meta-analysis of randomised controlled trials. World J Surg $\underline{40}$, 2305-18

Salminen P, Paajanen H, Rautio T, Nordström P, Aarnio M, Rantanen T, Tuominen R (2015) Antibiotic therapy vs appendectomy for treatment of uncomplicated acute appendicitis: The APPAC randomized clinical trial. JAMA $\underline{313}, 2340-48$

Schorr M (Hrsg.), Stumpf B, Hallfeldt K: Akute Appendizitis: eine prospektive Studie zur Evaluation des modifizierten Alvarado-Score, Deutsche Gesellschaft für Chirurgie; Springer Verlag Berlin, 363-366, 2000

Schumacher B (2015) AIR-Score bringt Licht ins Dunkel, Aerztezeitung $\underline{70 \mathrm{D}}$, 6

Schumpelick V (Hrsg), Bleese, NM, Mommsen, Braun, BJ, Winkler, R: Chirurgie: Kurzlehrbuch. 6. Auflage; Thieme Verlag Stuttgart, 2004, 506-540

Scott AJ, Mason SE, Arunakirinathan M, Reissis Y, Kinross JM, Smith JJ (2015): Risk stratification by the appendicitis inflammatory response score to guide decision-making in patients with suspected appendicitis. BJS $\underline{102}$ 563-72

Statistisches Bundesamt, „38\% der vollstationären Krankenhauspatienten wurde 2014 operiert", Pressemitteilung Nr. 357 vom 28.09.2015, URL: https://www.destatis.de/DE/Presse/Pressemitteilungen/2017/10/PD17_375_231.html, abgerufen am 31.01.2020 
Styrud J, Eriksson S, Nilsson I, Ahlberg G, Haapaniemi S, Neovius G, Rex L, Badume I, Granström L (2006): Appendectomy versus antibiotic treatment in acute appendicitis. a prospective multicenter randomized controlled trial. World J Surg $\underline{30}, 1033-37$

Tind S, Touborg Lassen A, Zimmerman-Nielsen E, Qvist N (2015): C-reactive protein and white blood cell count do not improve clinical decision-making in acute appendicitis. Dan Med $\mathrm{J} \underline{62}, 5167$

Von-Mühlen B, Franzon O, Beduschi MG, Kruel N, Lupselo D (2015): AIR score assessment for acute appendicitis. Arq Bras Cir Dig 28, 171-73

Vons C, Barry C, Maitre S, Pautrat K, Leconte M, Costaglioli B, Karoui M, Alves A, Dousset B, Valleur P, Falissard B, Franco D (2011): Amoxicillin plus clavulanic acid versus appendicectomy for treatment of acute uncomplicated appendicitis: An open-label, noninferiority, randomised controlled trial. Lancet $\underline{377}, 1573-79$ 


\section{LEBENSLAUF}

Ich, Florian Horst Armin Wendt, geborener Malinowsky wurde am 23.01.1979 als Sohn von Dr. med. Horst Malinowsky und seiner Frau Barbara Malinowsky, geborene Rau, in Kassel geboren.

Nach der Kindheit und der Grundschulzeit, welche ich in Lohfelden bei Kassel erlebte, setzte ich meine Schulzeit auf dem Friedrichsgymnasium in Kassel fort, wo ich 1998 das Abitur erlangte.

Es folgte eine 13-monatige Zivildienstzeit, die ich im Klinikum Kassel auf einer internistischen und herzchirurgischen Station in der Krankenpflege ableistete.

Im Wintersemester 1999 immatrikulierte ich mich an der Georg-August-Universität in Göttingen im Studiengang Medizin.

Während meines Studiums leistete ich Praktika und Famulaturen in Oldenburg, Lüneburg, in Tönning und in Berlin ab.

Am 15.3.2005 bestand ich den zweiten Abschnitt der ärztlichen Prüfung gefolgt von einem praktischen Jahr in Bremen und im Kantonsspital Obwalden in der Schweiz.

Am 20.12.2006 erlangte ich die Approbation als Arzt. Es folgte eine Assistenzarztzeit in den internistischen und notfallmedizinischen Abteilungen des Klinikums Kassel sowie in der allgemeinmedizinischen Praxis Dr. W. Lorenz in Vellmar, in welche ich am 1.7.2012 als Praxisteilhaber aufgenommen wurde.

Am 25.10.2010 erwarb ich die ärztliche Zusatzbezeichnung Notfallmedizin, am 15.12.2014 die Zusatzbezeichnung Naturheilverfahren und am 12.03.2018 die Zusatzbezeichnung Palliativmedizin.

Am 20.08.2011 heiratete ich die Ärztin Maren Wendt. Aus dieser Ehe gingen zwei Kinder hervor.

Seit 2016 arbeite ich neben meiner Tätigkeit als Allgemeinmediziner in der Abteilung von Professor Dr. Reith an der Agaplesion Diakonieklinik Kassel an meiner Promotion. 